\title{
Variability of Wind and Wind Power
}

\author{
Joaquin Mur-Amada and Ángel Bayod-Rújula \\ Zaragoza University \\ Spain
}

\section{Introduction}

The installed capacity for wind power is increasing substantially in response to the worldwide interest in low-emissions power sources and a desire to decrease the dependence on petroleum.

The European Union directive 2009/28/EC enforces the mandatory target of a $20 \%$ share of energy from renewable sources in overall Community energy consumption by 2020 and a mandatory $10 \%$ minimum target to be achieved by all Member States for the share of biofuels in transport petrol and diesel consumption by 2020. These targets may require between 30 and $40 \%$ of the electricity in the European Union to come from renewable energy sources by 2020 .

In the U.S., the world's top wind producer (The Guardian, 2008), wind currently makes up just one percent of the energy supply. Wind power generation share is expected to grow up to $20 \%$ in the USA by 2030 (EnerNex, 2006; U.S. D.O.E., 2008). Moreover, many U.S. states have legislated similarly ambitious renewable energy portfolio standards.

These goals were set without regard for the fact that many in the scientific community have concluded a theoretical wind penetration limit of only $20 \%$ due to the degradation of system reliability (DeCarolis et al., 2005). The Department of Energy states that there is no fundamental technical reason why 20 percent of wind energy cannot be assimilated into the grid by 2030. To help make its point, the agency debunks the reliability myth in its fact sheet on Wind Energy Myths (U.S. D.O.E. 2005).

According to (Feldman, 2009), the renewable output could leap to 40 percent of the Irish electricity share; in Denmark to 33 percent; in Portugal to 28 percent; and in Germany and Greece to 25 percent. After 2020, a higher proportion may be needed. A significant amount of this renewable electricity is likely to come from wind, and the variability of this power needs to be managed.

With this amount of wind generation, the future electricity markets could be very different to those of today: instead of thermal power stations dominating the system, the market could be dominated by large amounts of price-insensitive nuclear and wind power, combined with highly intermittent output from the wind farms (Pöyry PLC, 2009).

The extent of uncertainty and variability in wind generation makes this resource different from the traditional, dispatchable generation resources, with the result that wind power generation cannot be readily integrated into standard system operating procedures (IEA, 2009). At relatively low levels of installed capacity, wind turbines and the output from large wind farms can essentially be absorbed into traditional system operations without 
degrading system reliability. At the current higher projected levels of penetration, wind power requires more sophisticated mechanisms to maximize its participation in the power system without penalizing it for the unavoidably intermittent nature of its resource (Sovacool, 2009).

In some real time markets, and at low levels of penetration, wind is treated as negative load (J. Apt, 2007). But the perception of wind power is changing from being considered a negative load to a capacity resource. Wind power can be integrated into system and market operations as a generating resource that could provide not only energy but also capacity and ancillary services (Piwko et al., 2004).

\subsection{Relationship between wind power variability and its forecast}

Wind varies in space and in time. The forecasts try to predict this variation from climate dynamics and from the systematic behavior of the weather.

The inherent uncertainty and availability of the meteorological data decreases the accuracy of the next day's wind generation forecast (Anderson et al., 2008). The issue of uncertainty in wind generation can be addressed by improving the accuracy of forecasting the wind resource. In addition, advances in wind forecasting and turbine controls suggest that wind power can participate in ancillary service markets.

The simplest forecast of a stochastic process is the persistence principle: the expected value during next period $[t, t+\Delta t]$ is the average value of the previous period $[t-\Delta t, t]$. The mean square error of the persistence prediction is just the variance of the average process during the interval $[t-\Delta t, t]$.

Thus, the ratio of the forecast root squared error to the standard deviation of the variable predicted is just the performance of the forecast relative to the persistence model.

Usually, numerical weather prediction significantly outperforms persistence for horizons longer than 6 hours. For shorter horizons, statistical methods can be more adequate due to the lack of a dense network of weather sensors near the wind farms. In such cases, the characterization of wind power variability is essential.

\subsection{Influence of the wind variability on the grid}

Wind power presents the most economically viable renewable solution, apart from hydro power (DeCarolis et al., 2005). The utility system is designed to accommodate load fluctuations, which occur continuously. This feature also facilitates accommodation of wind plant output fluctuations when wind penetration is low.

In order to make the long-term growth of wind generation possible, the variability and the intermittency of wind power must be managed (Boyle, 2007). In Denmark, Northern Germany, and parts of Spain, wind supplies $20 \%$ to $40 \%$ of electric loads without sacrificing reliability.

Generally, wind power forecast are targeted to optimize the hourly power dispatch. However, the electric system has to cope with instantaneous variation of load, generation and equipment trips. Such variations are usually unpredictable and they are usually considered deviations from the expected power tendency.

The variability of wind power has several negative effects on the reliability and system operation of the electric grid as well as wind project economics (Constantinescu et al., 2009). The stability of the electric grid depends upon reliable and consistent power generation that is balanced to the load through unit commitment (interhour), economic dispatch (intrahour), 
and regulation (intraminute), and wind power is counterproductive towards that effort. Due to its stochastic nature, wind generation is not dispatchable and therefore cannot be called upon to serve load. As a result, the capacity credit of a wind farm is very small - even as low as $8 \%$ of nameplate capacity according to a probabilistic loss-of-load analysis (Milligan, 2000).

Greater reliance on wind power requires more ancillary services, especially responsive reserves, to match the lost generation and ramp rate of wind turbines when the wind dies down. One study of a typical wind farm indicated ramp rates up to $4.4 \%$ of capacity per second (Parson et al., 2001), implying a large burden on ancillary services. In fact, an empirical analysis of increasing wind penetration in the Pacific Northwest U.S. demonstrated that reserve requirements increased with the square of installed wind capacity, and the need for total reserve capacity doubled after just $2500 \mathrm{MW}$ of installed wind capacity (Parsons et al., 2004).

In some applications, the estimation of wind power variability can be as important as its prediction. The forecasted values are usually the hourly wind or the hourly power generated by one turbine or a cluster of them. Most forecast models predict only the average hourly wind or wind power and they are intended for the requirements of the electricity markets. Only a few models characterize the uncertainty of the forecast and quantify the instantaneous fluctuations inside the time period.

The main applications which benefit from variability assessment are:

- The control of wind turbines and wind farms, where the short timescales involved makes forecasting unpractical.

- Automatic generation control, automatic voltage control or changes in automatic taps on transformers, more concerned with interhourly variations, that are quite difficult to predict.

- Improving the power quality, more related to voltage variations and hence, instantaneous power variations.

- Optimum sizing of storage devices or of running reserves in isolated or weak systems, where electricity must be supplied even in the worst case scenario.

- In risk assessment and the safe operation of the grid. The system must cope with unexpected outcomes when the forecast has big uncertainty.

\subsection{Geographic diversity on wind power}

Both the generated power and the forecast error decrease as more wind power producers are aggregated. Due to the geographic dispersion of wind generators, some power variations and prediction errors can be partially cancelled by other errors in other locations.

On the one hand, the forecast errors can be very low in wide geographic areas. The power balance can be met provided the electricity transmission networks are strong enough to carry the undispatchable generated power from remote areas (Matevosyan, 2006; Holttinen et al., 2007).

On the other hand, many quality parameters of the grid must be met locally and the reinforcement of the electricity networks is costly and, sometimes, it is not feasible. In islands, the power balance cannot rely on geographical diversity and other measures are required to counteract the wind power variability.

The weather conditions may remain stable for relative long periods among shift weather changes. Quick local turbulent fluctuations are tougher to predict in time and place than 
some smooth weather evolution. In fact, a good parameter of the accuracy of the prediction is the error relative to the variance of the random variable to be predicted.

However, the wind power forecast accuracy is usually referred to the total installed wind power considered in the prediction. These figures must be considered with caution:

- A $15 \%$ prediction error of the hourly power one day ahead of a single wind farm can be an accurate forecast (Martí et al., 2006, Ramirez-Rosado et al., 2009).

- A $15 \%$ prediction error of the hourly power one day ahead in a big system is a poor forecast (Juban et al., 2008).

The variance of the wind power decreases when increasing the time period of the measure or the spatial diversity of the wind generators. Therefore, increasing the time or space horizon of the predictions lowers the absolute prediction error. The standard deviation to mean ratio, called coefficient of variation (CV) (Parsons et al., 2001; Wan et al. 2002), is also sensitive to the geographic, the time averaging and the prediction horizon, as can be seen in Table 1.

The table 1 compares output at the start and end of the indicated time period in terms of the percentage of total generation from each turbine group. Std. Dev. is the abbreviation for standard deviation. CV stands for coefficient of variation, the ratio of standard deviation respect the mean of wind power.

The power spectral density identifies which frequencies of variation are contributing to the variance (Apt, 2007). The coherence indicates the degree of partial cancellation of the oscillation among the turbines at different frequencies (Sørensen et al. 2008). These two magnitudes can explain the effect of the geographic and time averaging. In the spatial domain, high frequencies smooth out a wind farm's aggregate power output since the coherence of the turbines' outputs is low, while low spatial frequencies cause a coherent variation in the farm's turbines.

\begin{tabular}{|l|c|c|c|c|}
\hline & $\begin{array}{c}\mathbf{1 4} \\
\text { Turbines } \\
(\%)\end{array}$ & $\begin{array}{c}\mathbf{6 1} \\
\text { Turbines } \\
(\%)\end{array}$ & $\begin{array}{c}\mathbf{1 3 8} \\
\text { Turbines } \\
(\%)\end{array}$ & $\begin{array}{c}\mathbf{2 5 0 +} \\
\text { Turbines } \\
(\%)\end{array}$ \\
\hline \multicolumn{5}{|c|}{ 1-Second Interval } \\
\hline Average CV & 0.4 & 0.2 & 0.1 & 0.1 \\
\hline Std. Dev. & 0.5 & 0.3 & 0.2 & 0.1 \\
\hline \multicolumn{5}{|c|}{ 1-Minute Interval } \\
\hline Average CV & 1.2 & 0.8 & 0.5 & 0.3 \\
\hline Std. Dev. & 2.1 & 1.3 & 0.8 & 0.6 \\
\hline \multicolumn{6}{|c|}{ 10-Minute Interval } \\
\hline Average CV & 3.1 & 2.1 & 2.2 & 1.5 \\
\hline Std. Dev. & 5.2 & 3.5 & 3.7 & 2.7 \\
\hline \multicolumn{6}{|c|}{ 1-Hour Interval } \\
\hline Average CV & 7.0 & 4.7 & 6.4 & 5.3 \\
\hline Std. Dev. & 10.7 & 7.5 & 9.7 & 7.9 \\
\hline
\end{tabular}

Table 1 . Wind generation variability as a function of the number of generators and time interval (from "20\% wind energy by 2030: Increasing Wind Energy" (U.S. D.O.E, 2008) 


\subsection{Demand response and wind variability}

To a large extent, load exhibits similar characteristics -uncertainty and variability- to wind power (Apt, 2007). Load patterns though, have been more extensively studied for many years and so are better understood and more accurately forecasted than the wind resource. The purpose of this effort in load modelling is to understand load patterns well enough to operate the power system through the control of individual generation and transmission facilities, in order to serve load and maintain system reliability.

Thus, load is extensively modelled and other facilities are controlled to serve load, with relatively little effort made to control load itself. This trend is not absolute, as there are traditional utility mechanisms, such as interruptible contracts and direct load control, to reduce load at times when system reliability would otherwise be threatened. There is also persistent interest in developing mechanisms for more dynamic load response for both reliability and economic purposes.

Recent efforts to allow load to be more responsive to system conditions and a more active participant in electricity markets arise for multiple reasons (Cappers et al., 2009). In addition to giving customers incentives to decrease their demand in the short run to improve system reliability during times of system peak, demand response can be used in the long term to decrease required capacity expansion and lower total costs. Demand response is also an important and essentially absent element in electricity markets. If it were to be more widely implemented, market efficiency would be likely to improve. Many efforts are being made to demonstrate the feasibility and the convenience of smart grids.

\subsection{Estimated cost of wind power variability}

The estimated cost of the uncontrollability of the wind resource has been widely researched from governmental policy makers to Independent System Operators (Porter et al., 2007). An understanding of the impacts of the variable sources of renewable energy must take into account the wider issues associated with managing electricity systems (Lamont, 2008).

Modern integrated networks are designed to cope with 'shocks' such as the sudden loss of large thermal power stations and with uncertainties in consumer demand, such as those caused by televised sports events. As the tools to deal with these are already available, the key question is the extent to which the introduction of large amounts of wind energy will increase the overall uncertainty in matching supply and demand. This extra uncertainty means that additional short-term reserves are needed to guarantee the security of the system (Matos, 2009).

The variability of wind power also adversely affects wind project economics. A stochastic power source like wind is inherently less valuable than a deterministic source. Net payments to wind generators are reduced by balancing-costs to compensate for unfulfilled obligations to generate power (Holttinen, 2008).

(Hirst et al, 2004) determined that net payments in the USA to wind farms vary from \$32/MWh for very small wind farms to less than \$10/MWh for farms larger than $2000 \mathrm{MW}$. (Holttinen et al., 2007) states that at wind penetrations of up to $20 \%$ of gross demand (energy), system operating cost increases arising from wind variability and uncertainty amounted to about $1 \sim 4 € / \mathrm{MWh}$. This is $10 \%$ or less of the wholesale value of the wind energy.

The cost of grid reinforcements due to wind power is very dependent on where the wind power plants are located relative to load and grid infrastructure. The grid reinforcement costs from studies vary from $50 € / \mathrm{kW}$ to $160 € / \mathrm{kW}$ in (Holttinen et al., 2007). The costs are 
not continuous; there can be single very high cost reinforcements, and there can also be differences in how the costs are allocated to wind power.

According to (Milborrow, 2009), the extra cost in the UK of these reserves -with wind providing $20 \%$ of electricity consumption- is unlikely to be more than $£ 1.20 /$ MWh on electricity bills (a little over $1 \%$ on domestic bills). With $40 \%$ of electricity provided by wind, the corresponding figure would be $£ 2.80 / \mathrm{MWh}$.

A second costs of wind variability is the backup cost for periods of very low wind resource along extensive geographical areas. (Recharge, 2009) reported that the calculations made by Oxford University Environmental Change Institute showed that between 1970-2003, low wind speeds all across the whole UK - those too slow to generate energy - occurred simultaneously in the country only one hour per year on average. In other words, the total wind power in the UK varies, but a $0 \%$ generation is quite unlikely event. According to (Milborrow, 2009), wind energy does not require the introduction of special back-up provisions in the UK and its back-up costs are modest. Though the study was focused in the UK, the results are relevant worldwide, as characteristics of wind are broadly similar.

All generating plants make use of a common pool of backup plant that is typically around $20 \%$ of the peak demand on the electricity network. When wind is introduced, system operators do not rely on the rated power of all the installed wind farms being available at the times of peak demand, but a lower amount - roughly $30 \%$ of the rated capacity at low penetration levels, falling to about $15 \%$ at high penetration levels. This lower 'capacity credit' gives rise to a modest 'backup cost'. 'Constraint costs' arise when the output from the wind turbines exceeds the demand on the electricity network. They are unlikely to arise until wind energy is contributing around $25 \%$ of electricity requirements.

Overall, it is concluded that the additional costs associated with variability - with wind power providing up to about $40 \%$ of all electricity, are quite small. For example, if wind provides $22 \%$ of electricity in the UK by 2020, variability costs would increase the domestic electricity price by about $2 \%$, according to (Milborrow, 2009). Further increases in the level of wind penetration beyond that point are feasible and do not rely on the introduction of new technology.

There are numerous technical innovations at various stages of development that can mitigate the costs associated with variability. Improved methods of wind prediction are under development worldwide and could potentially reduce the costs of additional reserve by around $30 \%$. Most other mitigation measures reduce the costs of managing the electricity network as a whole. 'Smart grids', for example, cover a range of technologies that may reduce the costs of short-term reserves; additional interconnections with Europe, including 'Supergrids' also deliver system-wide benefits and aid the assimilation of variability.

Electric cars hold out the prospect of reduced emissions for the transport network as a whole and could act as a form of storage for the electricity network -for which the electricity generator would not have to pay.

With current technology, wind power plants can be designed to meet industry expectations such as riding through voltage dips, supplying reactive power to the system, controlling terminal voltage, and participating in system operation with output and ramp rate control.

Although some aspects of the management of wind variability can be controversial and costly, many utilities agree that there is no insuperable technical reason why high proportions of wind energy cannot be assimilated into the system (UK National Grid, 2009). There is a large body of literature on the topic (IEA, 2006) and the steady growth of wind power, worldwide, indicates that it is seen as a robust choice for reducing greenhouse gas emissions. 


\section{Classification of wind and wind power oscillations}

Oscillations due to wind speed variations can be classified according to their rate and their spatial extent. Slow fluctuations (in the range of tens of minutes and hours) are mainly due to meteorological dynamics and they are highly correlated among near wind farms.

Fast fluctuations have lower spatial correlation (Nichita et al., 2002; Petru \& Thiringer, 2002) and wind gust and turbulence effects are smoothed in the output of the wind farm. A swift gust arriving simultaneously to all turbines dispersed in an area of kilometres is also very uncommon. The correlated component of wind is estimated in (Rosas, 2003) from the Davenport type and Schlez and Infield's decay factors (Schlez \& Infield, 1998), showing that coherence for distances greater than $100 \mathrm{~m}$ is bellow $10^{-20}$ at tower shadow frequencies (between $0.5 \mathrm{~Hz}$ and $2 \mathrm{~Hz}$ ). In fact, the coherence for the usual dimension of a wind farm is low for oscillations quicker than $0,001 \mathrm{~Hz}$ (Sørensen et al., 2007). Thus, the fluctuations quicker than 10 minutes are low correlated among the turbines a wind farm.

Fast fluctuations of power output can be divided into cyclic components (tower shadow, wind shear, modal vibrations, etc.), weather dynamics and events (connection or disconnection of the turbine, change in generator configuration, etc.). Oscillations from a few minutes to power supply frequency are mainly linearly uncorrelated and their sum across a wind farm can be estimated using stochastic analysis commonly applied in other areas such as multipath fading in communication channels, clutter and target cross section in radars, interference in communication systems, etc. However, this approach is novel in wind energy. In (Welfonder, 1997) a transfer function of the wind farm power output respect the output of a single turbine is estimated with gain $N$ at low frequencies $(f<0.03 \mathrm{~Hz})$ and gain $\sqrt{N}$ at high frequencies $(f>0.09 \mathrm{~Hz})$. Micro-meteorological and dynamic fluid models can predict the correlated fluctuations which predominate at the very low frequencies. Fully correlated fluctuations scales proportional to the number of turbines $N$ whereas linearly uncorrelated fluctuations cancel partially among turbines and they scale up typically in a factor $\sqrt{ } N$, according to the central limit theorem.

The influence of blade position in a single turbine power output has been widely analyzed in the literature (Gordon-Leishman, 2002; Dolan \& Lehn, 2005; Dolan \& Lehn, 2006). According to (Cidrás et al. 2002), a very steady and very uniform wind in conjunction with a weak electrical network is necessary for synchronization to happen driven by voltage drops. Moreover, simultaneous tower shadow at all turbines in a wind farm is a very uncommon event. If the turbine oscillations are not synchronized, the rotor positions have random phases and the crossing of a blade in front of the turbine tower is a random event with constant probability rate. As wind characteristics are similar inside the farm, the magnitude of the cyclic components would be similar in all turbines.

Experimental measures (Mur-Amada et al., 2003) have shown that the cuasi-periodic aerodynamic torque oscillations are transformed into stochastic oscillations of electric power due to the complex wind turbine dynamics. The power oscillations of frequency bellow $0,03 \mathrm{~Hz}$ are greatly reduced at the farm output and the main source of variability in the wind power injected in the grid is the meteorological dynamics.

To sum up, this chapter focuses on the spatial and temporal variability of the wind for short horizons. Fast fluctuations of wind power during continuous operation of wind turbine are not an issue for utilities. Only in isolated or weak networks, or in the simultaneous tripping event of big amounts of wind power they are an issue. These results can be extended to several wind farms since the uncorrelated components increases when the distances among turbines become bigger. 


\section{Turbulence overview}

\subsection{Turbulence characterization}

At a very basic level, a turbulence flow can be interpreted as a population of many eddies (vortices), of different sizes and strengths, embedded in another and forever changing, giving a random appearance to the flow (Fig. 1). Two variables then play a fundamental role: $d$, the characteristic diameter of the eddies, and $\hat{u}$, their characteristic orbital velocity. Since the turbulent flow consist in many eddies, of varying sizes and speeds, $\hat{u}$ and $d$ do not assume each of a single value but vary within a certain range. In stationary, homogeneous and isotropic turbulence, that is, a turbulent flow that statistically appears unchanging in time, uniform in space and without preferential direction, all eddies of a given size (same $d$ ) behave more or less in the same way and can be thought of sharing the same characteristic velocity $\hat{u}$. In other words, we make the assumption that $\hat{u}$ is a function of $d$ (Fig. 2).

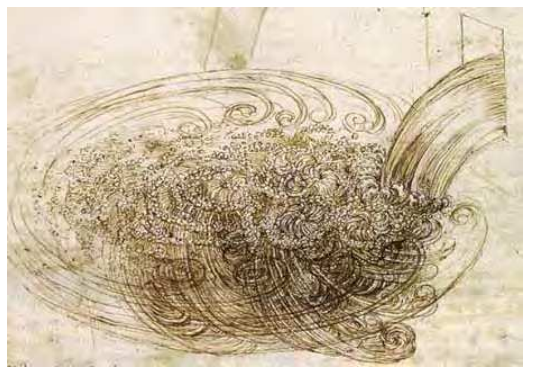

Fig. 1. Drawing of a turbulent flow by Leonardo da Vinci (1452-1519), who recognized that turbulence involves a multitude of eddies at various scales.

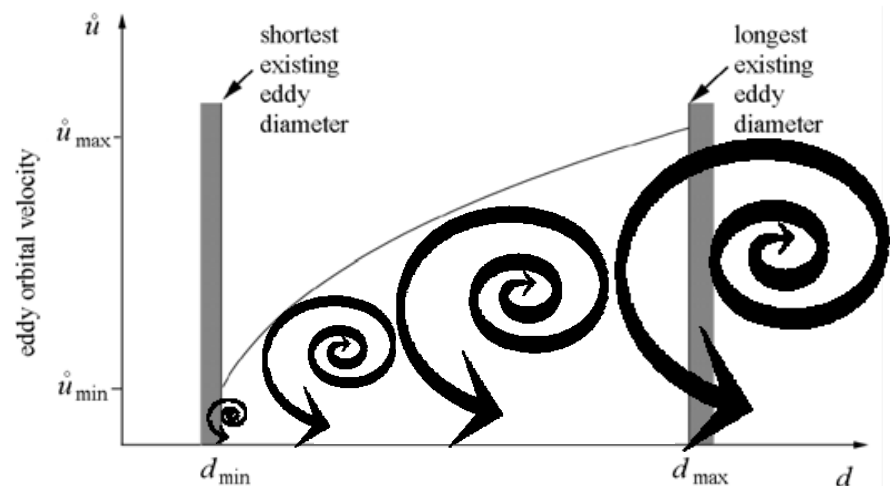

Fig. 2. Eddy orbital velocity versus eddy length scale in homogeneous turbulence. The largest eddies spin the fastest. Modified from (Cushman-Roisin, 2007; Watson, 2003).

\subsection{Wind spectra}

The fluctuations in the wind can be thought of as resulting from a composite of sinusoidally varying winds imposed on the mean steady wind. These sinusoidal variations will have a variety of frequencies and amplitudes. The term 'spectrum' is used to describe functions of frequency. Thus the function that characterizes turbulence as a function of frequency is 


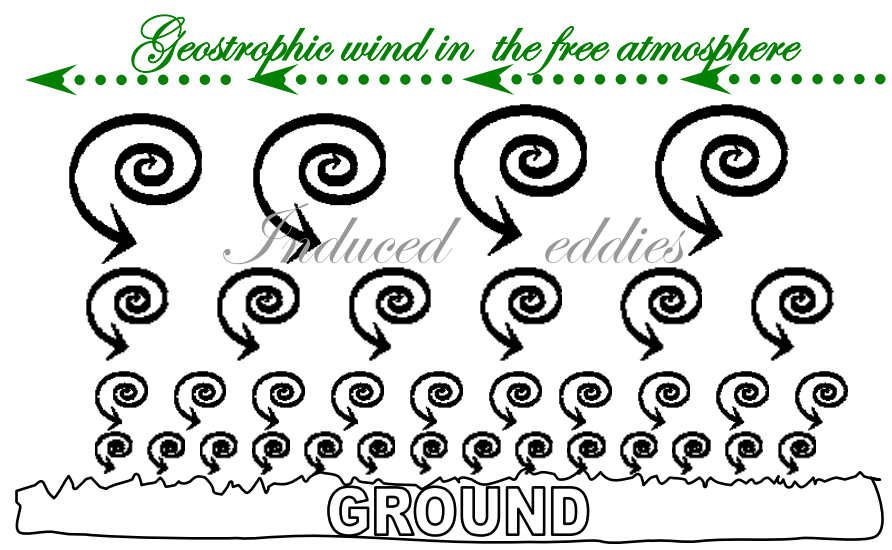

Fig. 3. Schematic of eddies as a function of height at atmospheric boundary layer. Modified from (Watson, 2003).

known as a 'spectral density' function. Since the average value of any sinusoid is zero, the amplitudes are characterized in terms of their mean square values. This type of analysis originated in electric power applications, where the square of the voltage or current is proportional to the power. The complete name for the function describing the relation between frequency and amplitudes of sine waves making up the fluctuating wind speed is therefore 'power spectral density' or PSD for short.

There are three points of particular importance to note regarding PSD's.

- The wind variance due to fluctuations within a frequency range may be found by integrating the $P S D_{U \text { wind }}^{+}(f)$ in that range.

- $\quad$ The integral of $P S D_{U w i n d}^{+}(f)$ over all frequencies is equal to the total wind variance.

- If two-sided $P S D(f)$ are used instead of $P S D+(f)$, the variance is twice the $P S D(f)$ if only positive frequencies are used in the integration domain.

Power spectral densities are often used in dynamic analyses. The variations of wind in the stream direction of the flow are usually characterized through the PSD of the longitudinal component of the instantaneous speed. A number of power spectral density functions are used as models in wind energy engineering when representative turbulence power spectral densities are unavailable for a given site. The mathematical forms for along-wind velocity spectra which are currently used in major current, or recent, wind codes and standards (Tamura et al., 2003) are due to von Karman, Kaimal and Davenport.

\subsection{Coherence models}

IEC 61400-1, 2005 specifies the coherence function (in absolute value) $\gamma_{I E C}(f)$ for two points $r$ and $c$ separated a distance $d$ in the rotor plane according to:

$$
\gamma_{I E C}(f)=\exp \left[-A \sqrt{\left(\frac{d_{r c} \cdot f}{\left\langle U_{\text {wind }}\right\rangle}\right)^{2}+\left(0,12 \frac{d_{r c}}{\ell_{\text {Uwind }}}\right)^{2}}\right]
$$


IEC 61400-1 recommends $A \approx 12$; (Frandsen et al., 2007) recommends $A \approx 5$ and (Saranyasoontorn et al., 2004) recommends $A \approx 9,7$. Note that this expression is intended for points in the area swept by the blades. Therefore, it is not intended for estimating the wind coherence at different turbines.

(Schlez \& Infield, 1998) derived an empirical model, based mainly on measurements with 18 $\mathrm{m}$ high masts with distances up to $102 \mathrm{~m}$ in the Rutherford Appleton Laboratory, UK. According to them, the coherence decreases exponentially at a site-specific rate respect wind travel time. The decay constants for lateral and longitudinal directions are, $A_{\text {ong }}$ and $A_{\text {lat }}$ respectively. $A_{\text {ong }}$ is the decay factor when the flow is longitudinal $\left(\alpha_{r c}=0\right) . A_{\text {lat }}$ is the decay factor when the flow is lateral, i.e. when the wind direction is perpendicular to the line between points $r$ and $c\left(\alpha_{r c}=\pi / 2 \mathrm{rad}\right)$.

Thus, a compound decay constant $A_{r c}$ can be estimated according to (2) for any arbitrary disposition of points $r$ and $c$ (see Fig. 4).

$$
A_{r c}=\sqrt{\left[A_{l o n g} \cos \left(\alpha_{r c}\right)\right]^{2}+\left[A_{l a t} \sin \left(\alpha_{r c}\right)\right]^{2}}
$$

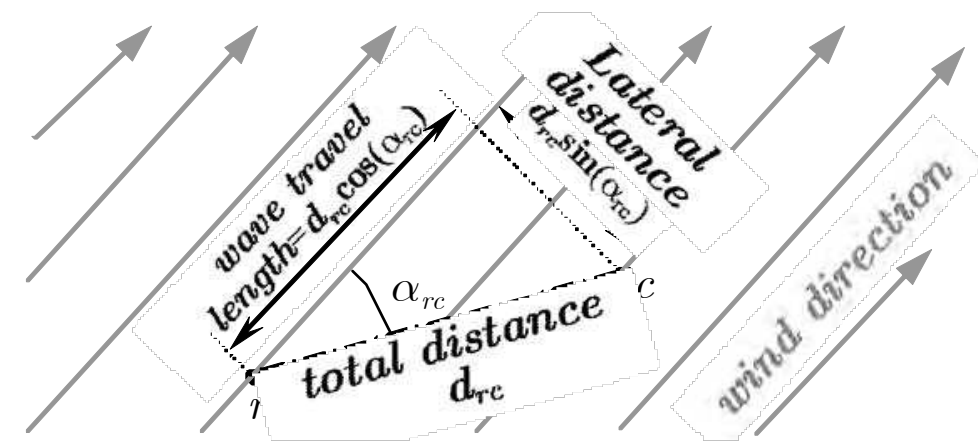

Fig. 4. Definition of distance $d_{r c}$ and angle $\alpha_{r c}$ between the points $r$ and $c$.

(Schlez and Infield, 1998) recommended for the Rutherford Appleton Laboratory $A_{\text {long }} \approx$ $(15 \pm 5) \sigma_{\text {Uwind }} /\left\langle U_{\text {wind }}\right\rangle$ and $A_{a t} \approx(17,5 \pm 5)(\mathrm{m} / \mathrm{s})^{-1} \sigma_{\text {Uwwind, }}$ where $\sigma_{\text {Uwind }}$ is the standard deviation of the wind speed in $\mathrm{m} / \mathrm{s}$.

(Saranyasoontorn et al., 2004) adjusted a coherence model from experimental data in LIST Test site at Bushland, Texas.

(Sørensen et al., 2008) fitted the lateral and longitudinal decay factors, $A_{\text {long }}=4$ and $A_{\text {lat }}=$ $\left\langle U_{\text {wind }}\right\rangle /(2 \mathrm{~m} / \mathrm{s})$, respectively, from measurements at $80 \mathrm{~m}$ height with up to $1.2 \mathrm{~km}$ distances in Høvsøre, Denmark. With these parameters, Sørensen et al. used a complex rooth coherence $\vec{\gamma}_{r c}(f)$ (adding an average phase delay to the absolute squared coherence $\left|\vec{\gamma}_{r c}^{2}(f)\right|$ proposed by Schlez and Infield, 1998). Since complex coherence is used, the phase of the coherence indicates the average delay between wind fluctuations at different points. Sørensen et al., 2002, used the Taylor's "frozen turbulence" model to compute the average time delay $\tau_{r c}$ as the time difference between the arrival to the points $r$ and $c$ of a flat wind wave front travelling at average wind speed. 


$$
\tau_{r c}=\frac{d_{r c} \cos \left(\alpha_{r c}\right)}{\left\langle U_{\text {wind }}\right\rangle}
$$

where $d_{r c}$ is the distance between points $r$ and $c$ (see Fig. 4).

Finally, the expression of the complex root coherence $\vec{\gamma}_{r c}(f)$ for Høvsøre is:

$$
\vec{\gamma}_{r c}(f)=\exp \left[-f\left(A_{r c} \frac{d_{r c}}{\left\langle U_{\text {wind }}\right\rangle}+j 2 \pi \tau_{r c}\right)\right]
$$

It can be derived that at low frequencies $\vec{\gamma}_{r c}(f)$ tends to unity with zero phase (fully positive correlated fluctuations) and at high frequencies $\vec{\gamma}_{r c}(f)$ tends to zero with random phase (uncorrelated fluctuations).

\section{Wind turbine torque}

Power oscillations are the ultimate response of generators to torque fluctuations due to spatial and temporal wind variations.

The turbine torque can be estimated from blade theory. Since either the blade section, neither the relative speed nor the angle of attack is constant along the blade from the root to the tip, torque must be integrated along the blade elements. The lift and drag coefficients for the whole blade can be parameterized for blade tip conditions.

A further simplification is to consider a torque coefficient $C_{q}(\lambda, \theta)$ depending only on the pitch angle $\theta$ and on tip speed ratio $\lambda$. In this work, the tip speed ratio is referred to an equivalent wind speed since the wind conditions vary along the swept area:

$$
\lambda=R \Omega_{\text {rotor }} / U_{e q^{\prime}}
$$

where $R$ is the rotor radius, $\Omega_{\text {rotor }}$ is the rotor angular speed and $U_{e q}$ is the equivalent wind speed. In a first approximation, $U_{e q}$ is the longitudinal wind speed component averaged along the swept area provided the shaft is aligned with the wind (Handsen et al., 2003 Handsen et al., 2007).

Thus, the turbine torque is:

$$
T_{\text {rotor }}=\frac{1}{2} \rho_{\text {air }} \pi R^{3} U_{e q}^{2} C_{q}(\lambda, \theta)
$$

where $\rho_{\text {air }}$ is the air density.

In a second approximation, $U_{e q}$ is defined as the wind speed applied to (5) and (6) which produces the same aerodynamic torque $T_{\text {rotor }}$ than the real wind field. Alternatively, the torque coefficient can be computed as the power coefficient divided by the tip speed ratio, $C_{q}(\lambda, \theta)=C_{P}(\lambda, \theta) / \lambda$.

\subsection{Definition of the equivalent wind, equivalent turbulence and effective quadratic turbulence a)Equivalent wind}

The equivalent wind $U_{e q}$ is an artifice defined as the uniform wind which would produce the same torque as the real wind field. According to (6), it can be computed from real torque as (7): 


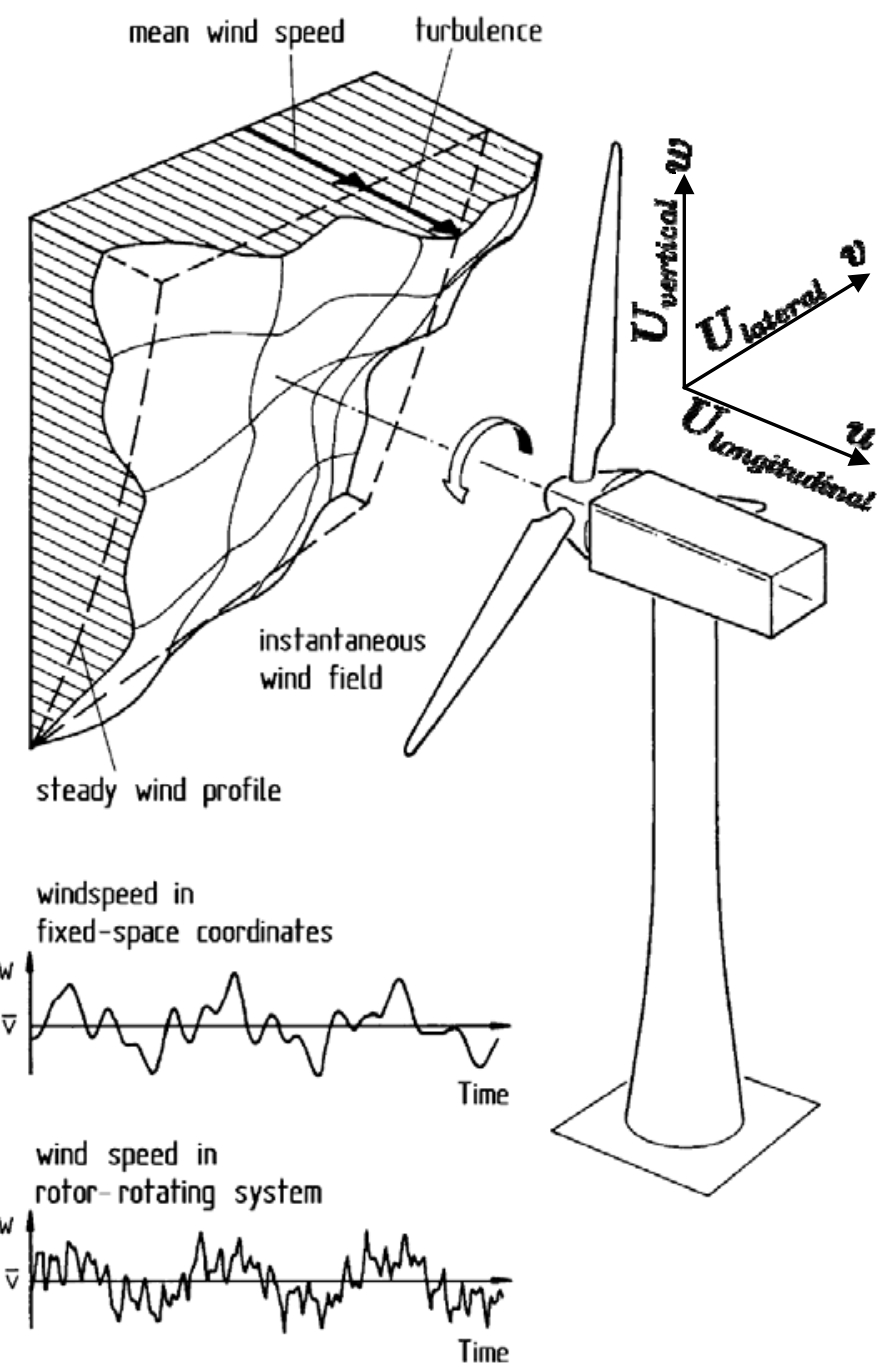

Fig. 5. Effect of an uneven wind-speed distribution over the swept rotor area on the upwind velocity of the rotating rotor blades. The lagrangian motion coordinates are added assuming the turbine is aligned with the wind. Taken from (Handsen et al., 2003).

$$
U_{e q}=\sqrt{\frac{2 T_{\text {rotor }}}{\rho_{\text {air }} \pi R^{3} C_{q}(\lambda, \theta)}}
$$

where $C_{q}(\lambda, \theta)$ is the turbine torque coefficient, $T_{\text {rotor }}$ is the torque in the low speed shaft of the wind turbine, $R$ is the rotor radius, $\Omega_{\text {rotor }}$ is the rotor angular speed and $\rho_{\text {air }}$ is the air density. Since the wind varies along the swept area (wind distribution is irregular), the tip speed ratio $\lambda$ must be computed also from (5). 
The simplification of using an equivalent wind is huge since the non-stationary threedimensional wind field is approximated by a signal which produces the same torque. Apart form accelerating notably the simulations, $U_{e q}$ describes in only one signal the effect of the turbulent flow in the drive train.

The actual wind speed $U_{\text {wind }}$ is measured at a point by an anemometer whereas the equivalent wind speed $U_{e q}$ is referred to the rotor surface (or more precisely, to the turbine torque). Since the Taylor's hypothesis of "frozen turbulence" is usually applicable, the spatial diversity of wind can be approximated to the pointwise time variation of wind times its mean value, $\left\langle U_{\text {wind }}\right\rangle$, and hence $U_{e q}$ can be considered a low-pass filtered version of $U_{\text {wind }}$ (plus the rotational sampling effect due to wind shear and tower shadow effect).

On the one hand, the meteorological science refers to the actual wind speed $U_{\text {wind }}$ since the equivalent wind $U_{e q}$ is, in fact, a mathematical artifice. On the other hand, turbine torque or power is customarily referred to the equivalent wind $U_{e q}$ instead of the 3-D wind field for convenience.

A good introduction about the equivalent wind can be found in (Martins et al. 2006). The complete characteristics of the wind that the turbine will face during operation can be found in (Burton et al., 2001).

The equivalent wind speed signal, $U_{e q}(t)$, just describes a smoothed wind speed time series at the swept area. For calculating the influence of wind turbulence into the turbine mechanical torque, it has to be considered the wind distribution along the swept area by a vector field (Veers, 1988). Blade iteration techniques can be applied for a detailed analysis of torques and forces in the rotor (Hier, 2006).

The anemometer dynamic response to fast changes in wind also influences measured wind (Pedersen et al., 2006). Most measures are taken with cup anemometers, which have a response lengths between 1 and $2 \mathrm{~m}$, corresponding to a frequency cut-off between $f_{c}=(10$ $\mathrm{m} / \mathrm{s}) / 10 \mathrm{~m}=1 \mathrm{~Hz}$ and $f_{c}=(10 \mathrm{~m} / \mathrm{s}) / 20 \mathrm{~m}=0,5 \mathrm{~Hz}$ for $10 \mathrm{~m} / \mathrm{s}$ average speed.

Apart from metrological issues, the spatial diversity of turbulent wind field reduces its impact in rotor torque. Complete and proved three dimensional wind models are available for estimating aerodynamic behavior of turbines (Saranyasoontorn et al., 2004; Mann, 1998; Antoniou et al., 2007). Turbulent models are typically used in blade fatigue load.

From the grid point of view, the main effect of spatial diversity is the torque modulation due to wind shear and tower shadow (Gordon-Leishman, 2002). Vertical wind profile also influences energy yield and it is considered in wind power resource assessment (Antoniou et al., 2007).

\section{Fundaments of the rotor spatial filtering}

The idea in the rotor wind model is to generate an equivalent wind speed which can be applied to a simplified aerodynamic model to simulate the torque on the wind turbine shaft. The rotor wind filter includes the smoothing of the wind speed due to the weighted averaging over the rotor.

The input of this filter is the wind $U_{\text {wind }}$ which would be measured at an anemometer installed at the hub height and the output is the estimated equivalent wind, $U_{e q 1}$, which is a smoothed version of the measured wind.

Neglecting the periodic components, the rotor block smoothing of wind turbine can be expressed as a wind turbine admittance function defined as: 


$$
\left|H_{1}(f)\right|^{2}=\frac{P S D_{\text {Uwind }}(f)}{P S D_{U e q_{1}}(f)}
$$

where $P S D_{U w i n d}(f)$ is the power spectral density of the wind measured at a point and $P S D_{U e q_{1}}(f)$ is the power spectral density of the equivalent wind (without the periodic components due to the cuasi-deterministic variation of torque with rotor angle).

The wind spectrum $P S D_{\text {Uwind }}(f)$ is equivalent to low-pass filters with a typical system order $r^{\prime}=5 / 6$ (i.e., the spectrum decays a bit slower than the output of a first-order low pass filter). Power output decreases quicker than the pointwise wind at $f>0.01 \mathrm{~Hz}$ (Mur-Amada et al. 2003) and this is partially due to the spatial distribution of turbulence, the high inertia and the viscous-elastic coupling of turbine and generator through the gear box (Engelen, 2007). Complex vibration dynamics influence power output and a simple model with two coupled mass (equivalent to a second-order system) is insufficient to represent the resonance modes of blades and tower.

The square modulus of the filter can be computed from the filter Laplace transform $H_{1}^{\prime}(s)$ :

$$
\left|H_{1}(f)\right|^{2}=H_{1}^{\prime}(j 2 \pi f)\left[H_{1}^{\prime}(j 2 \pi f)\right]^{*}
$$

The phase of the filter indicates the lag between the wind at the anemometer and at the turbine hub. The phase of the filter does not affect $P S D_{U e q_{1}}(f)$ since wind process is stationary and, accordingly, the phase is arbitrary. The lag difference of equivalent wind among turbines at points $r$ and $c$ will be considered through complex coherence $\vec{\gamma}_{r c}(f)$, irrespective of the argument of $H_{1}(f)$.

The frequencies of interest for flicker and blade fatigue are in the range of tenths of hertz to $35 \mathrm{~Hz}$. These frequencies correspond to sub-sound and sound (inertial subrange) and they have wavelengths comparable to the rotor diameter. The assumption that such fluctuations correspond to plane waves travelling in the longitudinal direction and arriving simultaneously at the rotor plane is not realistic. Therefore, quick fluctuations do not reach the rotor disk simultaneously and fluctuations are partially attenuated by spatial diversity. In brief, $H_{1}^{\prime}(s)$ is a low-pass filter with meaningless phase.

The smoothing due to the spatial diversity in the rotor area is usually accounted as an aerodynamic filter, basically as a first or second order low-pass filter of cut-off frequency $\sim 0,1224\left\langle U_{\text {wind }}\right\rangle / R$ respect an ideal and unperturbed anemometer measure (Rosas, 2003). For multimegawatt turbines, the rotor filters significantly fluctuations shorter than one minute with a second order decay (cut-off frequency in the order of 0,017 Hz). The turbine vibrations are much more noteworthy than the turbulence at frequencies higher than $0,1 \mathrm{~Hz}$.

The presence of the ground surface hinders vertical development in larger eddies. The lateral turbulence component is responsible for turbulence driven wind direction changes, but it is a secondary factor in turbine torque fluctuations. Moreover, according IEC 61400-1, 2005, vertical and transversal turbulence has a significantly smaller length scale and lower magnitude. Thus, the vertical and lateral component of turbulence averaged along the turbine rotor can be neglected in turbine torque in the first instance. 


\section{Equivalent wind of turbine clusters}

\subsection{Average farm behavior}

Sometimes, a reduced model of the whole wind farm is very useful for simulating a wind farm in the grid. The behavior of a network with wind generation can be studied supplying the farm equivalent wind as input to a conventional turbine model connected to the equivalent grid.

The foundations of these models, their usual conventions and their limitations can be seen in (Akhmatov \& Knudsen, 2002; Kazachkov \& Stapleton, 2004; Fernandez et al, 2006). The average power and torque in the turbines and in the farm are the same on per unit values. This can be a significant advantage for the simulation since most parameters do not have to be scalled. Notice that if electrical values are not expressed per unit, currents and network parameters have to be properly scalled.

For convenience, all the $N$ turbines of a wind farm are represented with a single turbine of radius $R_{\text {farm }}$ spinning at angular speed $\Omega_{\text {farm }}$. The equivalent power, torque, wind, rotor speed, pitch and voltage are their average among the turbines of the farm. Thus, the equivalent turbine represents the average operation among the farm turbines.

If the turbines are different or their operational conditions are dissimilar, the averages are weighted by the turbine power (because the aim of this work is to reproduce the power output of farms). Elsewhere, the farm averaged parameters can by approximated by a conventional arithmetic mean.

\subsection{Model based in equivalent squared wind}

Assuming that the equivalent wind at the different wind turbines behaves as a multivariate Gausian process with spectral covariance matrix:

$$
\Xi_{U e q}(f)=\left[\vec{\gamma}_{i j}(f) \sqrt{P S D_{U e q, i}(f) P S D_{U e q, j}(f)}\right]
$$

Thus, the $P S D_{U e q, f a r m}(f)$ of the equivalent squared wind for the farm can be computed as:

$$
P S D_{\text {Ueq, farm }}(f)=\vec{b}_{\text {farm }}^{T} \Xi_{U e q}(f) \vec{b}_{\text {farm }}=\sum_{i=1}^{N} \sum_{j=1}^{N} b_{i} b_{j} \vec{\gamma}_{i j}(f) \sqrt{P S D_{U e q, i}(f) P S D_{U e q, j}(f)}
$$

where $\vec{\gamma}_{i j}(f)$ is the complex coherence of the equivalent wind of turbines $i$ and $j$ at frequency $f$, and the contribution of the turbine $i$ to the farm wind is $b_{i}$.

If all the turbines experience similar equivalent wind spectra $-P S D_{U e q, i}(f) \approx P S D_{U e q}(f)$ - and their contribution to the farm is similar $-b_{i} \approx 1 / N$ - then the following approximate formula is valid:

$$
P S D_{U e q, f a r m}(f) \approx \frac{P S D_{U e q}(f)}{N^{2}} \sum_{i=1}^{N} \sum_{j=1}^{N} \vec{\gamma}_{i j}(f)
$$

Notice that $\vec{\gamma}_{i i}(f)=1$ and $0 \leq\left|\vec{\gamma}_{i j}(f)\right| \leq 1$. Since the real part of $\vec{\gamma}_{i j}(f)$ is usually positive or close to zero (i.e., non-negative correlation of fluctuations), $P S D_{U e q, f a r m}(f)$ is generally between the behavior of perfectly correlated and independent fluctuations at the turbines. 


$$
\begin{gathered}
\frac{P S D_{U e q}(f)}{N} \lesssim P S D_{U e q, f a r m}(f) \leq \frac{P S D_{U e q}(f)}{N^{2}} \\
\text { since } 0 \lesssim \operatorname{Re}\left[\vec{\gamma}_{i j}^{\prime}(f)\right]
\end{gathered}
$$

\subsection{Equivalent wind of turbines distributed along a geographical area}

In (4), a model of complex root coherence $\vec{\gamma}_{r c}(f)$ was introduced based on the works of (Schlez \& Infield, 1998) in the Rutherford Appleton Laboratory and (Sørensen et al., 2008) in the Høvsøre offshore wind farm. In (12), a formula was derived assuming all the turbines experience a similar wind and they have similar characteristics.

In this section, the decrease of variability of the equivalent wind of a geographical area due to its spatial diversity is computed in (14) from the variability at a single turbine or a single farm and from the complex root coherence $\vec{\gamma}_{r c}(f)$.

Formula (14) assumes that wind turbines are approximately evenly spread over the area corresponding to the integrating limits. Even though the former assumptions are oversimplifications of the complex meteorological behavior neither it considers wakes, (14) indicates the general trend in the decrease of wind power variability due to spatial diversity in bigger areas. Notice that $P S D_{\text {Ueq, turbine }}(f)$ is assumed to be representative of the average turbulence experienced by turbines in the region and hence, it must account average wake effects. Even though the model is not accurate enough for many calculations, it leads to expression (19) that links the smoothing effect of the spatial diversity of wind generators in an area and its dimensions.

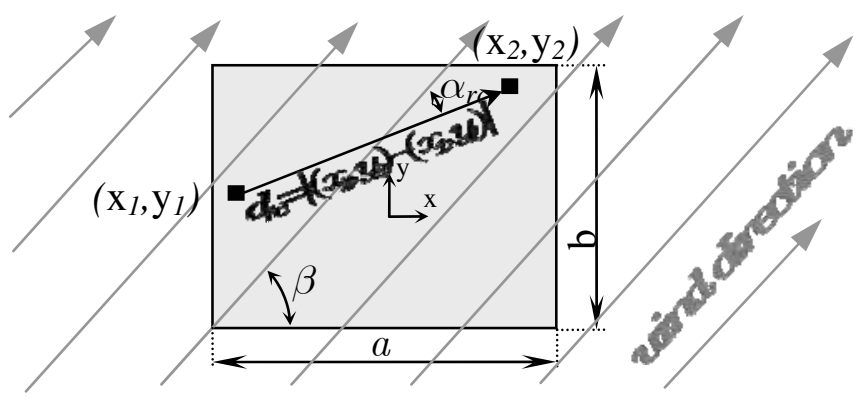

Fig. 6. Wind farm dimensions, angles and distances among wind farm points for the general case.

The coherence $\vec{\gamma}_{r c}(f)$ between points $r=\left(x_{1}, y_{1}\right)$ and $c=\left(x_{2}, y_{2}\right)$ inside the wind farm can be derived from Fig. 6 and formulas (2), (3) and (4). The geometric distance between them is $d_{r c}=\left|\left(x_{2}, y_{2}\right)-\left(x_{1}, y_{1}\right)\right|=\left[\left(y_{2}-y_{1}\right)+\left(x_{2}-x_{1}\right)^{2}\right]^{1 / 2}$ and the angle between the line that links the two points and the wind direction is $\alpha_{r c}=\beta-\operatorname{ArcTan}\left[\left(y_{2}-y_{1}\right) /\left(x_{2}-x_{1}\right)\right]$. In the general case, the equivalent wind taking into account the spatial diversity can be computed extending formula (12) to the continuous case: 


$$
\frac{P S D_{\text {Ueq,area }}(f)}{P S D_{\text {Ueq,turb }}(f)} \approx \frac{\int_{-b / 2}^{b / 2} \int_{y_{1}}^{b / 2} \int_{-a / 2}^{a / 2} \int_{x_{1}}^{a / 2} \vec{\gamma}_{r c}\left(f, d_{r c}, \alpha_{r c}\right) d x_{2} d x_{1} d y_{2} d y_{1}}{\int_{-b / 2}^{b / 2} \int_{y_{1}}^{b / 2} \int_{-a / 2}^{a / 2} \int_{x_{1}}^{a / 2} d x_{2} d x_{1} d y_{2} d y_{1}}
$$

where the quadruple integral in the denominator is a forth of the squared area, i.e., $a^{2} b^{2} / 4$.

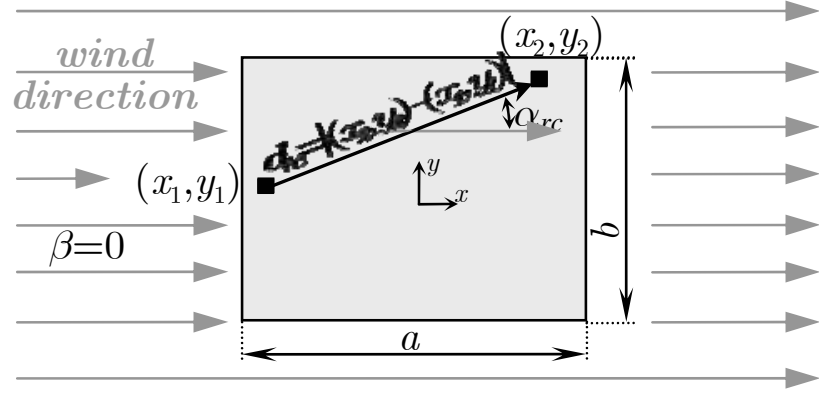

Fig. 7. Wind farm parameters when wind has the $x$ direction $(\beta=0)$.

Due to the complexity of $d$ and $\alpha_{r c}$ and the estimation of $\vec{\gamma}_{r c}\left(f, d_{r c}, \alpha_{r c}\right)$ in formula (4), no analytical closed form of (14) have been found for the general case.

In case wind has $x$ direction as in Fig. 7, then the coherence has a simpler expression:

$$
\vec{\gamma}_{r c}\left(f, d_{r c}, \alpha_{r c}\right)==\exp \left[\frac{-f}{\left\langle U_{\text {wind }}\right\rangle}\left(\sqrt{\left[A_{\text {long }}\left(x_{2}-x_{1}\right)\right]^{2}+\left[A_{\text {lat }}\left(y_{2}-y_{1}\right)\right]^{2}}+j 2 \pi\left(x_{2}-x_{1}\right)\right)\right]
$$

The presence of the squared root in (15) prevents from obtaining an analytical $P S D_{\text {Ueq,area }}(f)$. In case $a A_{\text {long }} b A_{\text {lat }}$ the region can be considered a thin column of turbines transversally aligned to the wind. This is the case of many wind farms where turbine layout has been designed to minimize wake loss (see Fig. 9) and areas where wind farms or turbines are sited in mountain ridges, in seashores and in cliff tops perpendicular to the wind. Since $A_{\text {long }}\left(x_{2}-x_{1}\right) \quad A_{\text {lat }}\left(y_{2}-y_{1}\right)$, then $P S D_{\text {Ueq,area }}(f)$ can be computed analytically as:

$$
\frac{P S D_{\text {Ueq,lat area }}(f)}{P S D_{\text {Ueq, turb }}(f)} \approx f_{1}\left(\frac{A_{\text {lat }} b f}{\left\langle U_{\text {wind }}\right\rangle}\right)
$$

where $f_{1}(x)=2\left(-1+e^{-\mathrm{x}}+\mathrm{x}\right) / x^{2}$

In case $a A_{\text {long }} b A_{\text {lat }}$ the region can be considered a thin row of wind farms longitudinally aligned to the wind. This is the case of many areas where wind farms are disposed in a gorge, canyon, valley or similar where wind is directed in the feature direction (see Fig. 9). Since $A_{\text {long }}\left(x_{2}-x_{1}\right) \quad A_{\text {lat }}\left(y_{2}-y_{1}\right)$, then $P S D_{\text {Ueq,area }}(f)$ can be computed analytically as: 


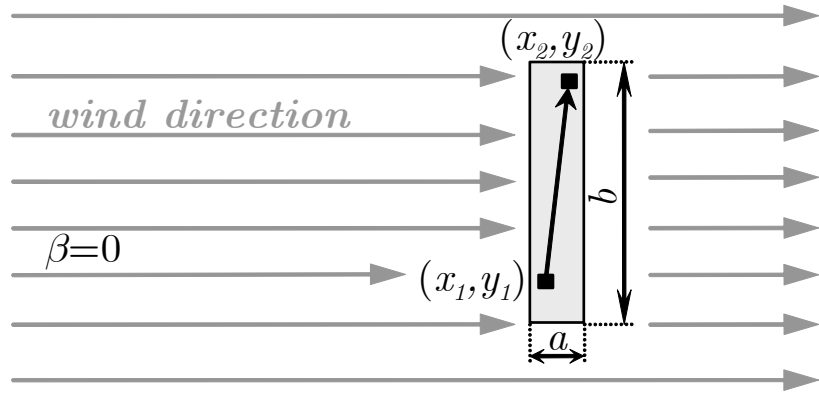

Fig. 8. Wind farm with turbines aligned transversally to the wind.

$$
\frac{P S D_{\text {Ueq,long area }}(f)}{P S D_{\text {Ueq, }, \text { turb }}(f)} \approx f_{2}\left(\frac{A_{\text {long }} a f}{\left\langle U_{\text {wind }}\right\rangle}, A_{\text {long }}\right)
$$

where $f_{2}\left(\frac{A_{\text {long }} a f}{\left\langle U_{\text {wind }}\right\rangle}, A_{\text {long }}\right)=\operatorname{Re}\left\{f_{1}\left(\frac{\left(A_{\text {long }}+j 2 \pi\right) a f}{\left\langle U_{\text {wind }}\right\rangle}\right)\right\}$

which can be expressed with real functions as:

$$
f_{2}\left(\nu, A_{\text {long }}\right)=\frac{(\nu-1)+(\nu+1)\left(\frac{2 \pi}{A_{\text {long }}}\right)^{2}+\left\{\left(1-\left(\frac{2 \pi}{A_{\text {long }}}\right)^{2}\right) \operatorname{Cos}\left[\frac{2 \pi \nu}{A_{\text {long }}}\right]-\frac{4 \pi}{A_{\text {long }}} \operatorname{Sin}\left[\frac{2 \pi \nu}{A_{\text {long }}}\right]\right\} e^{-\nu}}{\frac{1}{2} \nu^{2}\left(1+\left(2 \pi / A_{\text {long }}\right)^{2}\right)^{2}}
$$

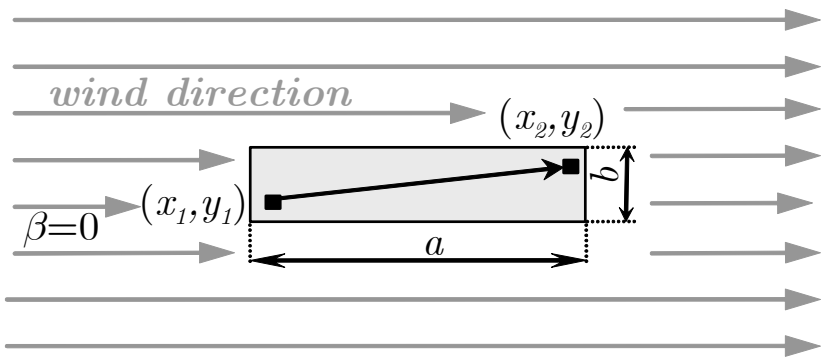

Fig. 9. Wind farm with turbines aligned longitudinally to the wind.

Notice that (17) includes an imaginary part that is due to the frozen turbulence model in formula (4). A wind wave travels at wind speed, producing an spatially average PSD that depends on the longitudinal length $a$ relative to the wavelength. For long wavelengths compared to the longitudinal dimension of the area $\left(A_{\text {long }} 2 \pi\right)$, the imaginary part in (17) can be neglected and (17) simplifies to (16). This is the case of the Rutherford Appleton 
Laboratory, where (Schlez \& Infield, 1998) fitted the longitudinal decay factor to $A_{\text {long }} \approx$ $(15 \pm 5)\left\langle U_{\text {wind }}\right\rangle / \sigma$ Uwind for distances up to $102 \mathrm{~m}$.

But when the wavelengths are similar or smaller than the longitudinal dimension, $\left(A_{\text {long }} \lesssim 2 \pi\right)$, then the fluctuations are notably smoothed. This is the case of the Høvsøre offshore wind farm, where (Sørensen et Al., 2008) fitted the longitudinal decay factor to $A_{\text {long }}$ $=4$ for distances up to $2 \mathrm{~km}$. In plain words, the disturbances travels at wind speed in the longitudinal direction, not arriving at all the points of the area simultaneously and thus, producing an average wind smoother in longitudinal areas than in transversal regions.

In the normalized longitudinal and transversal distances have the same order, then (14) can be estimated as the compound of many stacked longitudinal or transversal areas (see Fig. 10):

$$
\begin{aligned}
\left|H_{3}(f)\right|^{2} & =\frac{P S D_{\text {Ueq,rect area }}(f)}{P S D_{\text {Ueq, }, \text { turb }}(f)}=\frac{P S D_{\text {Ueq,long area }}(f)}{P S D_{\text {Ueq, lat area }}(f)} \frac{P S D_{\text {Ueq, lat area }}(f)}{P S D_{\text {Ueq,turb }}(f)} \approx \\
& \approx f_{1}\left(\frac{A_{\text {lat }} b f}{\left\langle U_{\text {wind }}\right\rangle}\right) f_{2}\left(\frac{A_{\text {long }} a f}{\left\langle U_{\text {wind }}\right\rangle}, A_{\text {long }}\right)
\end{aligned}
$$

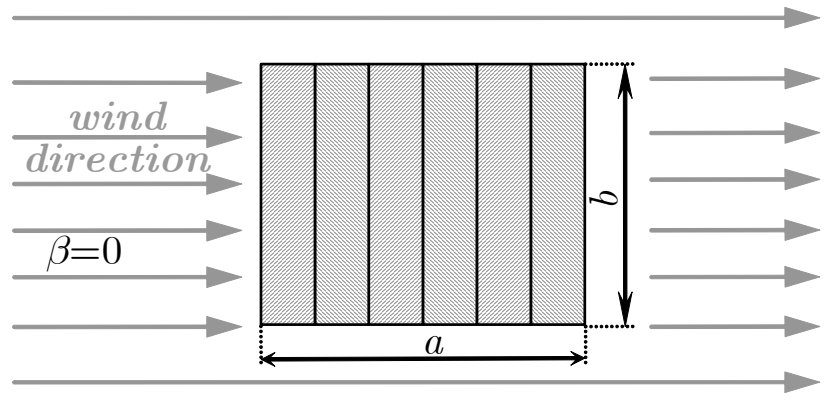

Fig. 10. Rectangular area divided in smaller transversal areas.

The approximation (19) is equivalent to consider the Manhattan distance ( $\mathrm{L}_{1}$ or city-block metric) instead of the Euclidean distance ( $\mathrm{L}_{2}$ metric) in the coherence $\vec{\gamma}_{r c}(15)$ :

$$
\sqrt{\left[A_{\text {long }}\left(x_{2}-x_{1}\right)\right]^{2}+\left[A_{\text {lat }}\left(y_{2}-y_{1}\right)\right]^{2}} \sim A_{\text {long }}\left(x_{2}-x_{1}\right)+A_{\text {lat }}\left(y_{2}-y_{1}\right)
$$

\subsection{Equivalent wind smoothing due to turbine spatial layout}

Expression (19) is the squared modulus of the transfer function of the spatial diversity smoothing in the area. $H_{3}(f)$ corresponds to the low-pass filters in Fig. 11 with cut-off frequencies inversely proportional to the region dimensions.

The overall cut-off frequency of the spatially averaged wind is obtained solving $\left|H_{3}(f)\right|^{2}=1 / 4$. Thus, the cut-off frequency of transversal wind farms (solid black line in Fig. 11) is: 


$$
f_{\text {cut }, \text { lat }}=6.83 \frac{\left\langle U_{\text {wind }}\right\rangle}{b A_{\text {lat }}}
$$

In the Rutherford Appleton Laboratory $(\mathrm{RAL}), A_{\text {lat }} \approx(17,5 \pm 5)(\mathrm{m} / \mathrm{s})^{-1} \sigma_{\text {Uwind }}$ and hence $f_{\text {cut }, \text { lat }}$ $\approx(0,42 \pm 0,12)\left\langle U_{\text {wind }}\right\rangle /\left(\sigma_{\text {Uwind }} b\right)$. A typical value of the turbulence intensity $\sigma_{\text {Uwind }} /\left\langle U_{\text {wind }}\right\rangle$ is around 0,12 and for such value $f_{\text {cut,lat }} \sim(3.5 \pm 1) / b$, where $b$ is the lateral dimension of the area in meters. For a lateral dimension of a wind farm of $b=3 \mathrm{~km}$, the cut-off frequency is in the order of $1,16 \mathrm{mHz}$.

In the Høvsøre wind farm, $A_{\text {lat }}=\left\langle U_{\text {wind }}\right\rangle /(2 \mathrm{~m} / \mathrm{s})$ and hence $f_{\text {cut lat }} \approx 13,66 / b$, where $b$ is a constant expressed in meters. For a wind farm of $b=3 \mathrm{~km}$, the cut-off frequency is in the order of $4,5 \mathrm{mHz}$ (about four times the estimation from RAL).

In RAL, $A_{\text {long }} \approx(15 \pm 5) \sigma_{\text {uwind }} /\left\langle U_{\text {wind }}\right\rangle$. A typical value of the turbulence intensity $\sigma_{\text {Uwind }}$ $/\left\langle U_{\text {wind }}\right\rangle$ is around 0,12 and for such value $A_{\text {long }} \approx(1,8 \pm 0,6)$.

$$
f_{\text {cut }, \text { long }}=1,1839 \frac{\left\langle U_{\text {wind }}\right\rangle}{a A_{\text {long }}} \underset{A_{\text {long }}=1.8}{=}=0.6577 \frac{\left\langle U_{\text {wind }}\right\rangle}{a}
$$

For a wind speed of $\left\langle U_{\text {wind }}\right\rangle \sim 10 \mathrm{~m} / \mathrm{s}$ and a wind farm of $a=3 \mathrm{~km}$ longitudinal dimension, the cut-off frequency is in the order of $2,19 \mathrm{mHz}$.

In the Høvsøre wind farm, $A_{\text {long }}=4$ (about twice the value from RAL). The cut-off frequency of a longitudinal area with $A_{\text {long }}$ around 4 (dashed gray line in Fig. 11) is:

$$
f_{\text {cut, long }}=2.7217 \frac{\left\langle U_{\text {wind }}\right\rangle}{a A_{\text {long }}} A_{\text {long }} \sim 4=0.6804 \frac{\left\langle U_{\text {wind }}\right\rangle}{a}
$$

For a wind speed of $\left\langle U_{\text {wind }}\right\rangle \sim 10 \mathrm{~m} / \mathrm{s}$ and a wind farm of $a=3 \mathrm{~km}$ longitudinal dimension, the cut-off frequency is in the order of $2,26 \mathrm{mHz}$.

In accordance with experimental measures, turbulence fluctuations quicker than a few minutes are notably smoothed in the wind farm output. This relation is proportional to the dimensions of the area where the wind turbines are sited. That is, if the dimensions of the zone are doubled, the area is four times the original region and the cut-off frequencies are halved. In other words, the smoothing of the aggregated wind is proportional to the longitudinal and lateral distances of the zone (and thus, related to the square root of the area if zone shape is maintained).

In sum, the lateral cut-off frequency is inversely proportional to the site parameters $A_{\text {lat }}$ and the longitudinal cut-off frequency is only slightly dependent on $A_{\text {long }}$. Note that the longitudinal cut-off frequency show closer agreement for Høvsøre and RAL since it is dominated by frozen turbulence hypothesis.

However, if transversal or longitudinal smoothing dominates, then the cut-off frequency is approximately the minimum of $f_{\text {cut,lat }}$ and $f_{\text {cut,long }}$. The system behaves as a first order system at frequencies above both cut-off frequencies, and similar to $1 / 2$ order system in between $f_{\text {cut }, \text { lat }}$ and $f_{\text {cut,long }}$. 


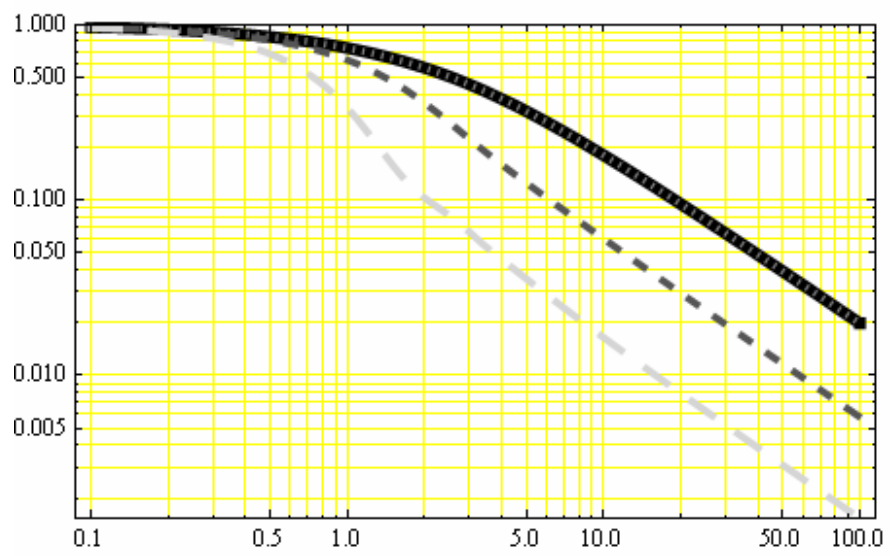

Fig. 11. Normalized ratio $P S D_{\text {Ueq,area }}(f) / P S D_{\text {Ueq,turbine }}(f)$ for transversal (solid thick black line) and longitudinal areas (dashed dark gray line for $A_{\text {long }}=4$, long dashed light gray line for $\left.A_{l o n g}=1,8\right)$. Horizontal axis is expressed in either longitudinal and lateral adimensional frequency a $A_{\text {long }} f /\left\langle U_{\text {wind }}\right\rangle$ or $b A_{\text {lat }} f /\left\langle U_{\text {wind }}\right\rangle$.

\section{Spectrum and coherence estimated from the weather station network}

The network of weather stations provides a wide coverage of slow variations of wind. Many stations provide hourly or half-hourly data. These data is used in the program WINDFREDOM (Mur-Amada, 2009) to compute the wind spectra and the coherences between nearby locations.

Quick fluctuations of wind are more related to the turbine integrity, structural forces and control issues. But they are quite local, and they cancel partially among clusters of wind farm. The slower fluctuations are more cumbersome from the grid point of view, since they have bigger coherences with small phase delays.

The coherence and the spectrum of wind speed oscillations up to 12 days are analyzed, as an illustrative example, at the airports of the Spanish cities of Logroño and Zaragoza. Both cities are located in the Ebro River and share a similar wind regime. The weather stations are $140,5 \mathrm{~km}$ apart (see Fig. 12) and the analysis is based on one year data, from October 2008 to October 2009.

The spectrograms in Fig. 13 and Fig. 14 show the evolution of the power spectrum of the signal, computed from consecutive signal portions of 12 days. The details of the estimation procedure can be found in the annexes of this thesis.

Wind spectra and coherence has been computed from the periodogram, and the spectrograms of the signals are also shown to inform of the variability of the frequency content. The quartiles and the 5\% and 95\% quantiles of the wind speed are also shown in the lower portions of in Fig. 13 and Fig. 14. The unavailable data have been interpolated between the nearest available points. Some measurements are outliers, as it can be noticed from the 5\% quantiles in Fig. 13 and Fig. 14, but they have not been corrected due to the lack of further information. 


\begin{tabular}{l|l|l|l|l|l|l|l|l|} 
Map & $\begin{array}{l}\text { Station } \\
\text { availability }\end{array}$ & $\begin{array}{l}\text { Station } \\
\# 1\end{array}$ & $\begin{array}{l}\text { Station } \\
\# 2\end{array}$ & $\begin{array}{l}\text { Spect. } \\
\text { Ratio }\end{array}$ & $\begin{array}{l}\text { Coherence } \\
\text { phase }\end{array}$ & $\begin{array}{l}\text { Coherence } \\
\text { module }\end{array}$ & $\begin{array}{l}\text { Fit of cohe- } \\
\text { rence models }\end{array}$ & $\begin{array}{l}\text { About this } \\
\text { program }\end{array}$
\end{tabular}

You can change the geographic area dragging the locator out of the center of the map and using the zoom control at the bottom

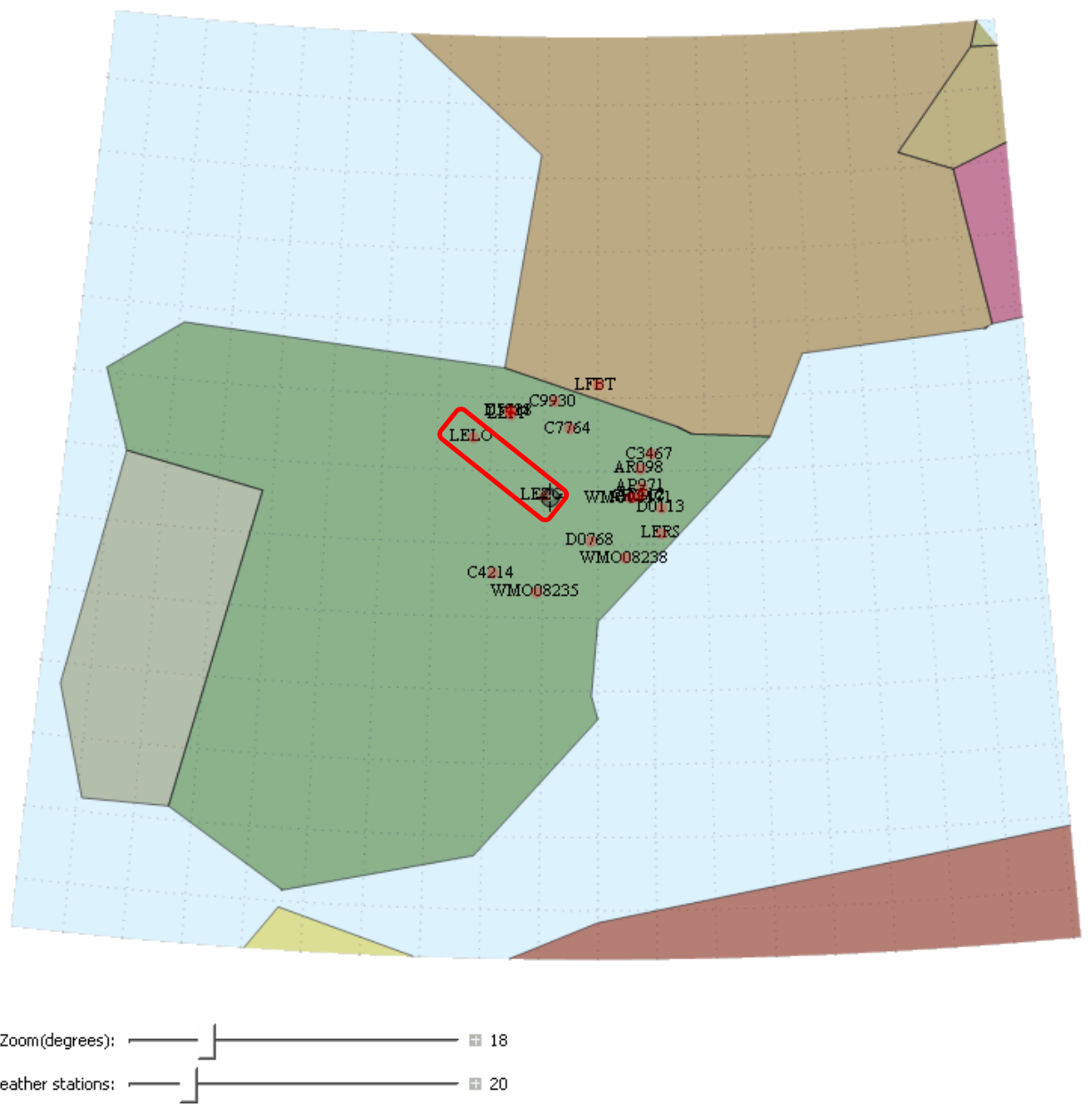

Fig. 12. Map from WINDFREDOM program with the location of Zaragoza and Logroño in the Iberian Peninsula. 
Wind speed [km/h] in LEZG from Sun 5 Oct 2008 17:30:00. to Mon 5 Oct 2009 14:30:00
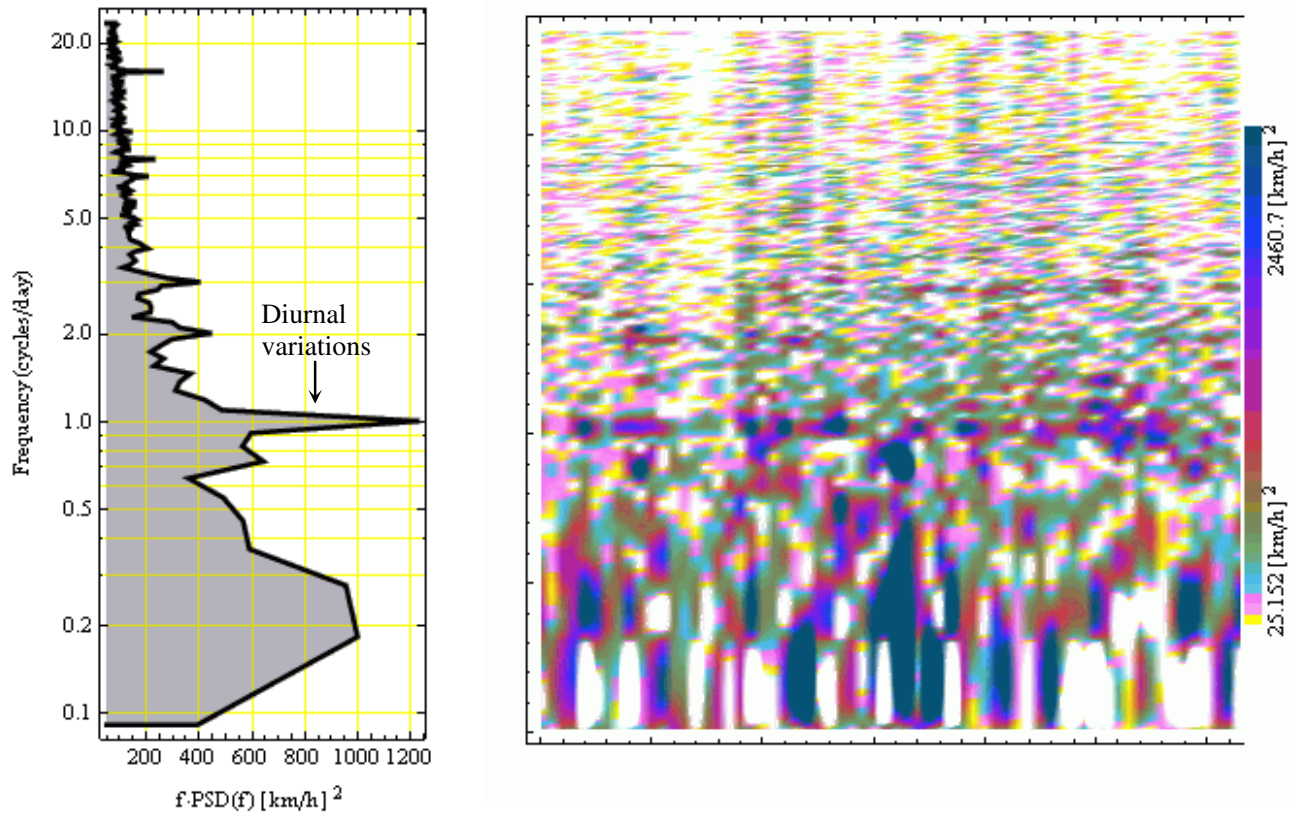

Periodogram or $\mathrm{f} * \mathrm{PSD}(\mathrm{f})$ at top left $\uparrow$, Spectrogram or $f * P S D(f, t)$ at top right $\nearrow$ and signal at bottom right $\rightarrow$ (quantiles 5\%,25\%,50\%,75\%,95\%).

The shadowed area of the periodogram and the darkness of the spectrogram represent the variance of the signal (the PSD is multiplied by $\mathrm{f}$ in plots with logarithmic frequency axis).

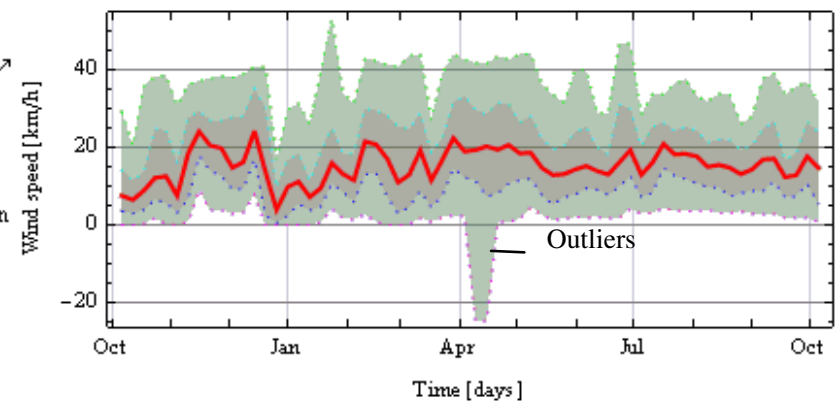

DESCRIPTIVE STATISTICS OF THE TRE SERIES

Number of samples: 17128. sampled at frequency $f=47$. samples $/$ day .

Mean $\mu=16.292 \mathrm{~km} / \mathrm{h}$. Standard deviation $\sigma=11.481 \mathrm{~km} / \mathrm{h}$.

Median $=14.76 \mathrm{~km} / \mathrm{h}$. Mode $(\mathrm{s})$ or commonest $\mathrm{value}(\mathrm{s})=\{3.6\} \mathrm{km} / \mathrm{h}$.

Heibul fit: shape parameter $k=1.4408$ and scale parameter $\lambda=17.952 \mathrm{~km} / \mathrm{h}$.

Kurtosis $=3.303$

Fig. 13. Periodogram and spectrogram of Zaragoza airport (Spain) estimated with WINDFREDOM program. 
Wind speed [km/h] in LELO from Sun 5 Oct 2008 18:00:00. to Mon 5 Oct 2009 14:00:00
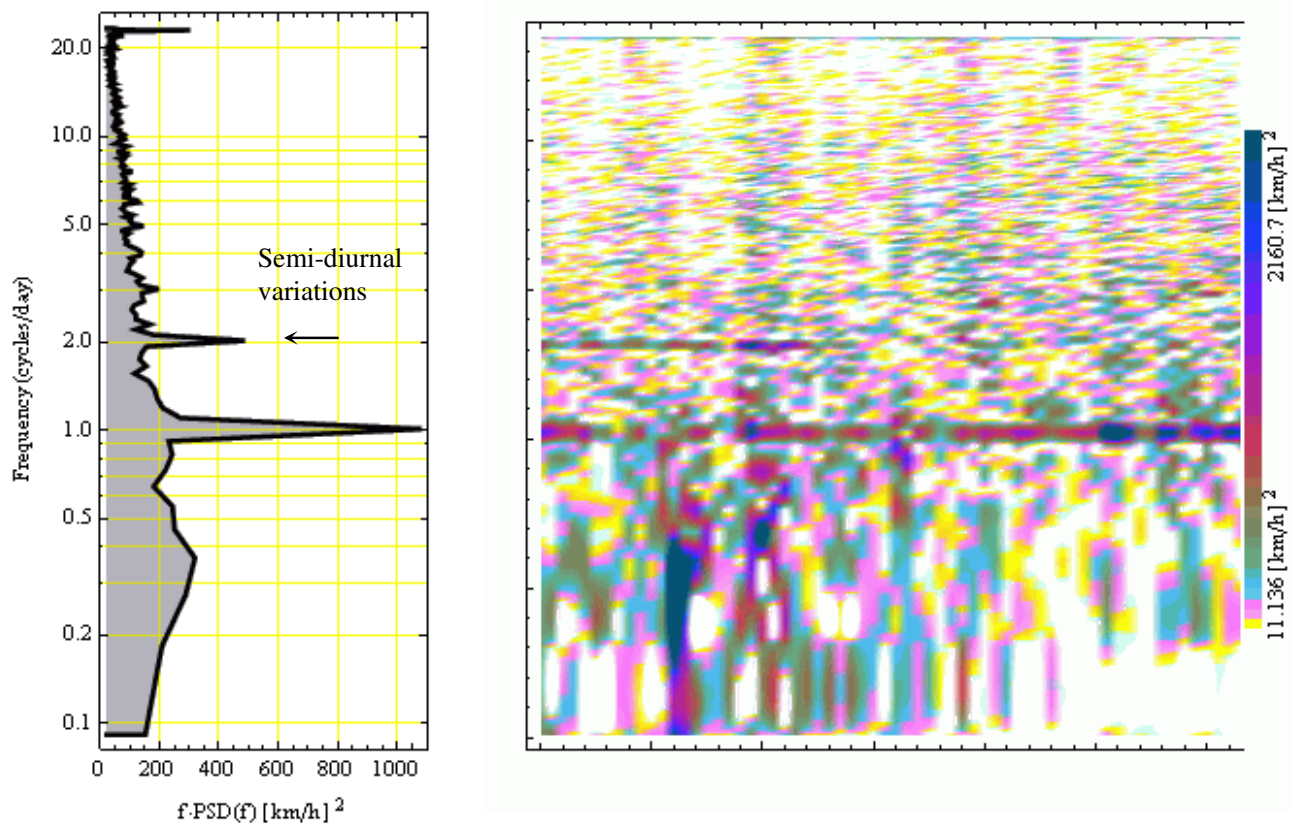

Periodogram or $\mathrm{f} * \mathrm{PSD}(\mathrm{f})$ at top left $\uparrow$, Spectrogram or $\mathrm{f} * \mathrm{PSD}(\mathrm{f}, \mathrm{t})$ at top right $\succ$ and signal at bottom right $\rightarrow>$ (quantiles $5 \%, 25 \%, 50 \%, 75 \%, 95 \%$ ).

The shadowed area of the periodogram and the darkness of the spectrogram represent the variance of the signal (the PSD is multiplied by $f$ in plots with logarithmic frequency axis).

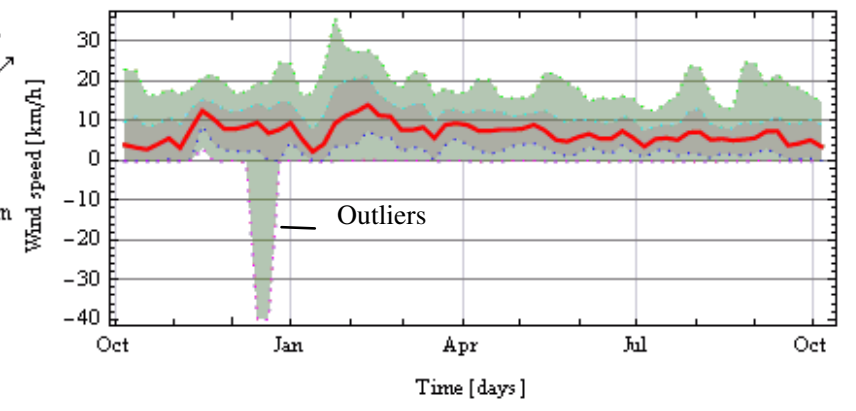

DESCRIPTIVE STATISTICS OF THE TRE SERIES

Humber of samples: 13863. sampled at frequency $f=39$. samples/day.

Mean $\mu=7.8883 \mathrm{~km} / \mathrm{h}$. Standard deviation $\sigma=6.9413 \mathrm{~km} / \mathrm{h}$.

Median $=7.56 \mathrm{~km} / \mathrm{h}$. Mode $\{\mathrm{s}\}$ or commonest $\mathrm{value}[\mathrm{s}\}=\{0\} \mathrm{km} / \mathrm{h}$.

Weibul fit: shape parameter $k=1.139$ and scale parameter $\lambda=8.2651 \mathrm{~km} / \mathrm{h}$.

Kurtosis $=4.4311$

Fig. 14. Periodogram and spectrogram of Logroño airport (Spain) estimated with WINDFREDOM program. 
The diurnal and semi-diurnal variation peaks can be recognized in clearly in the periodograms of Fig. 13 and Fig. 14 (gray graph on the left) or as dark-bluish horizontal lines in the spectrogram (colour image on the right). The oscillation magnitude is not constant along one year because the horizontal lines get lighter or darker along the time.

The ratio between the periodograms and spectrograms of Fig. 13 and Fig. 14 is shown in Fig. 15. The wind in Zaragoza airport meteorological station (LEZG for short) is the double in average than in the weather station of Logroño airport (LELO for sort). The average ratio is about $0,4 \sim 0,6$, indicating that the ratio of oscillation amplitudes are around $\sqrt{ } 0,4 \sim \sqrt{ } 0,6$. The coefficient of variation (standard deviation divided by the mean) is $87 \%$ in Logroño and $70 \%$ in Zaragoza.

The quartiles of the time series at Logroño and Zaragoza (lower graph in Fig. 15) show significant differences. The red shadow indicates the interquartile range of Zaragoza and the thick red line is its median (the blue colours correspond to Zaragoza). The wind in Logroño (in blue) is about half the wind in Zaragoza in average.

The wind variations in each station show different features eventually. Some variations are replicated on the other station but with some non-systematic delay and with different magnitude. These features are the reason of the relatively small coherence of the two stations.

In practice, the oscillations observed in one station are seen, in some extent, in other station with some delay or in advance. The coherence $\vec{\gamma}_{\# 1, \# 2}$ is a complex magnitude with modulus between 0 and 1 and a phase, which represent the delay (positive angles) or the advance (negative angles) of the oscillations in the second weather station respect the first one (considered the reference). Since the spectrum of a signal is complex, the argument of the coherence $\vec{\gamma}_{r c}(f)$ is the average phase difference of the fluctuations.

The coherence $\vec{\gamma}_{r c}(f)$ indicates the correlation degree and the time pattern of the fluctuations. The modulus is analogous to the correlation coefficient of the spectrum lines from both locations. If the ratio among complex power spectrums shown in Fig. 15 is constant (in modulo and in phase), then the coherence is the unity and its argument is the average phase difference. If the complex ratio is random (in modulo or in phase, then the coherence is null.

However, the wind direction is not considered in this estimation, but it has a great impact on the coherence estimate. The time delay between oscillations $\tau$ depends greatly on the wind direction. Thus, the phase difference of the fluctuations, $\varphi=2 \pi f \tau$, can change notably and this would lead to very low coherences. If there are several preferential wind directions, the phase difference can experience great variability. In such cases, a more detailed model maybe using Markov states indicating prevailing wind directions- is needed.

The red/purple colours in Fig. 15 indicate that phase difference is near 0 up to 0,5 cycles/day (small delay of fluctuations). However, the phase difference at frequencies above 2 cycles/day is quite big, indicating that the timing sequence of the fluctuations has varied along the study period (one year). 
Data from Sun 5 Oct 2008 17:30:00. to Mon 5 Oct 2009 14:30:00

The distante between LEZG (station \#1) and LELO (station \#2) is $140.49 \mathrm{~km}$.

\begin{tabular}{l|ccccc} 
& Latitute & Longitude & Elevation [m] & Series mean & Samples per day \\
\hline LEZG & 41.667 & -1. & $258 . \mathrm{m}$ & $16.292 \mathrm{~km} / \mathrm{h}$ & 48 \\
LELO & 42.45 & -2333 & $363 . \mathrm{m}$ & $7.8883 \mathrm{~km} / \mathrm{h}$ & 36
\end{tabular}

The periodogram and spectrogram of LELO have been divided by the ones of LEZG: * A ratio bigger than unity indicate that the fluctuations of frequency $f$ observed in LELO are bigger than in LEZG.

* A ratio smaller than unity indicate that the fluctuations of frequency $f$ observed in LELO are smaller than in LEZG.

In the lower right plot, the quartiles of Wind speed [km/h] in LEZG are shown in red. The quantiles of Wind speed $[\mathrm{km} / \mathrm{h}]$ in LELO are shown in blue.
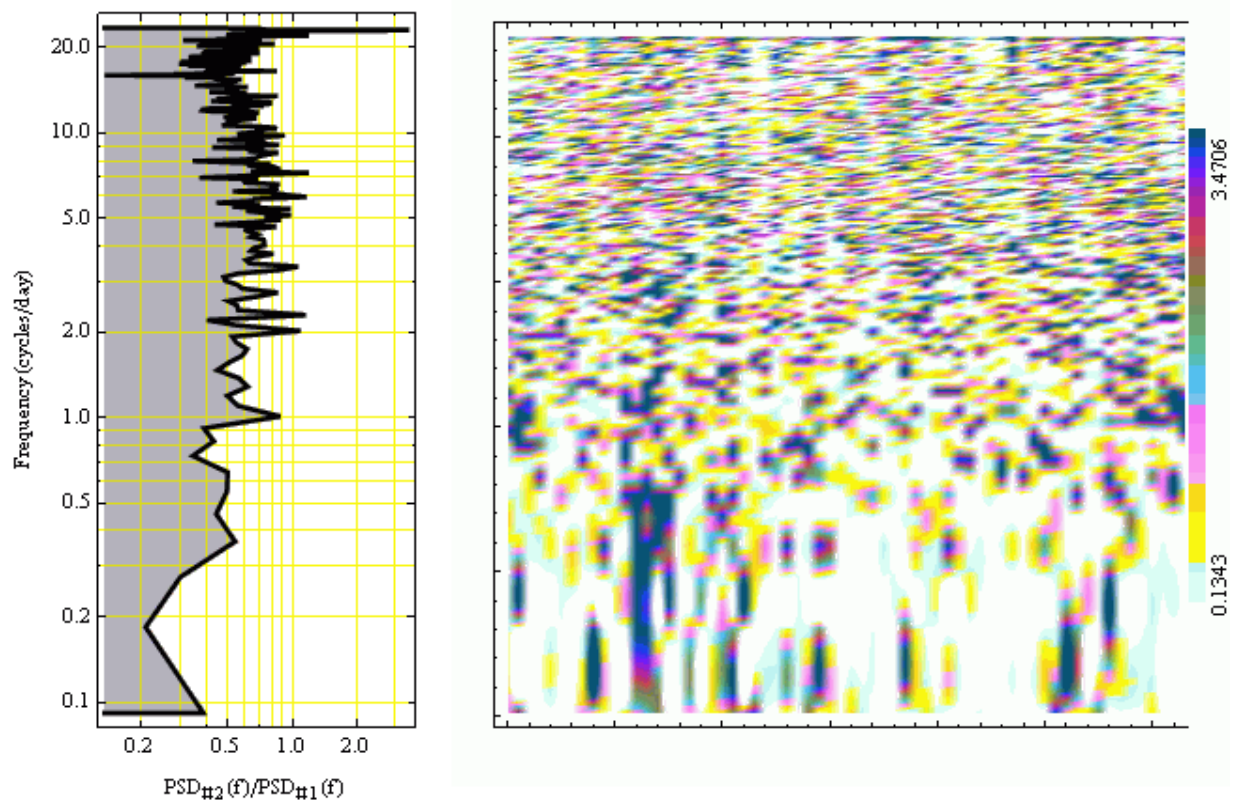

Periodogram ratio at top left $\uparrow$, $\mathrm{PSD}_{\sharp 2}(\mathrm{f}) / \mathrm{PSD}_{\mathbb{H} 1}(\mathrm{f})$

Spectrogram ratio at top right $\nearrow$

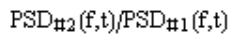

and the quartiles of Wind speed $[\mathrm{km} / \mathrm{h}]$

(LEZG in red, LELO in blue) at bottom right $\rightarrow$.

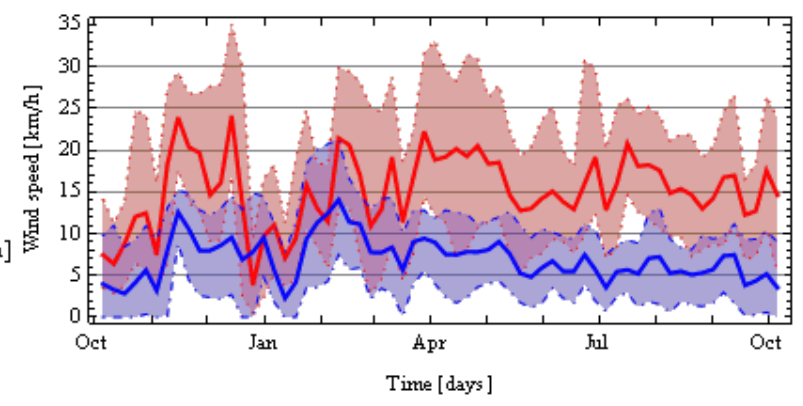

Fig. 15. Periodogram and spectrogram of Logroño airport divided by the ones of Zaragoza airport (estimated by WINDFREDOM program). 
The phase difference between the spectrum of LEZG and LELO is computed to estimate the lag between the oscilations in both stations.

* A phase difference positive indicate that the fluctuations of $f$ frequency are observed (in average) first in LEZGand then in LELO and viceversa.

*The average time lag can be computed as lagsphase $/(2 \pi \cdot f)$ when the phase is expressed in radians. $\Rightarrow$ In general, slow fluctuations show a phase proportional to frequency indicating that the slow fluctuations are observed with a constant time delay between stations.

*A random phase indicates that the fluctuations happen first indiferently in any station without a simple temporal link.

$\Rightarrow$ In general, fast fluctuations show non-systematic phases indicating that they are local.
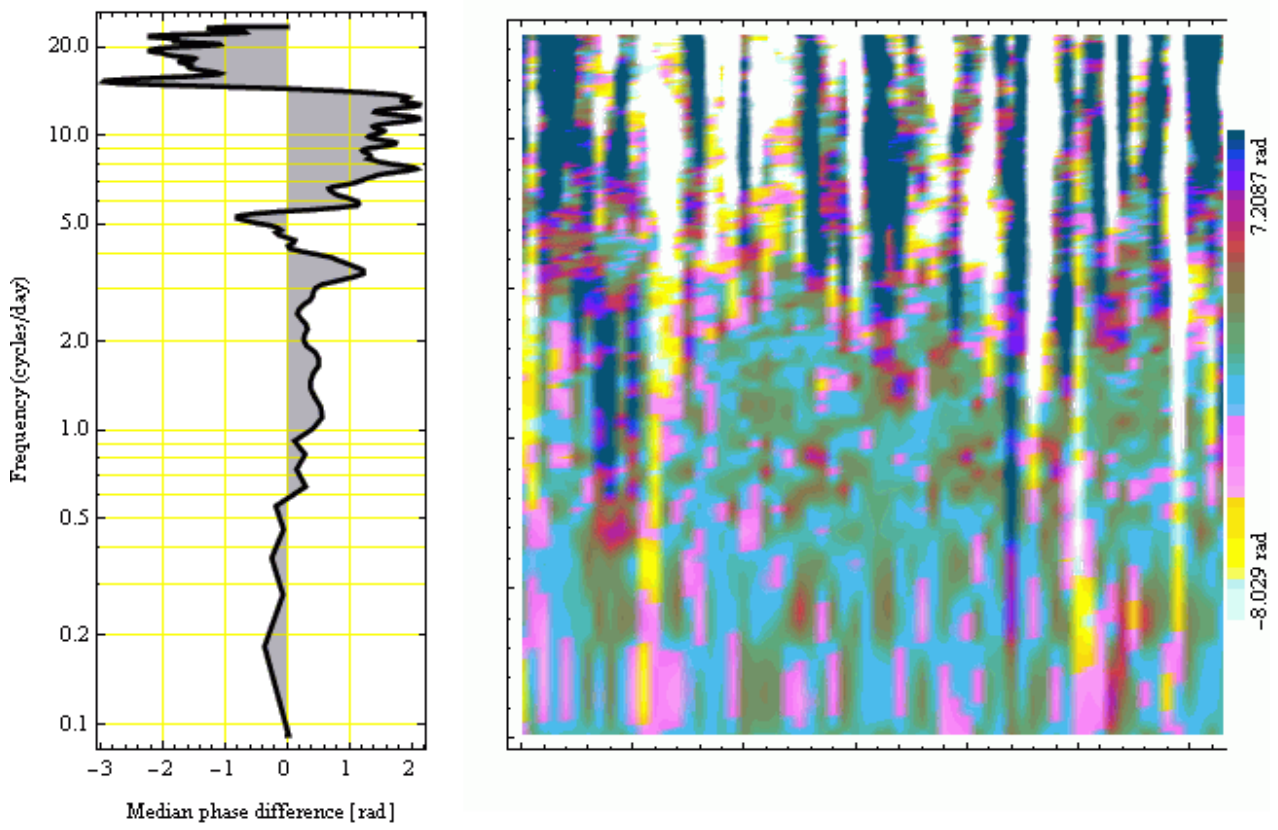

Average spectrum phase difference between stations $\# 1$ and $\# 2$ at top left $\uparrow$, $\left\langle\mathrm{SFFT}_{\# 1}(\mathrm{f}, \mathrm{t})-\mathrm{SSFFT}_{\# 2}(\mathrm{f}, \mathrm{t})\right\rangle$

Spectrum phase difference at top right $\nearrow$ $\Delta \mathrm{SFFT}_{\# 1}(\mathrm{f}, \mathrm{t})-\left\llcorner\mathrm{SFFT}_{\# 2}(\mathrm{f}, \mathrm{t})\right.$

and the quartiles of Wind speed $[\mathrm{km} / \mathrm{h}]$ (LEZG in red, $L E L O$ in blue) at bottom right $\rightarrow$.

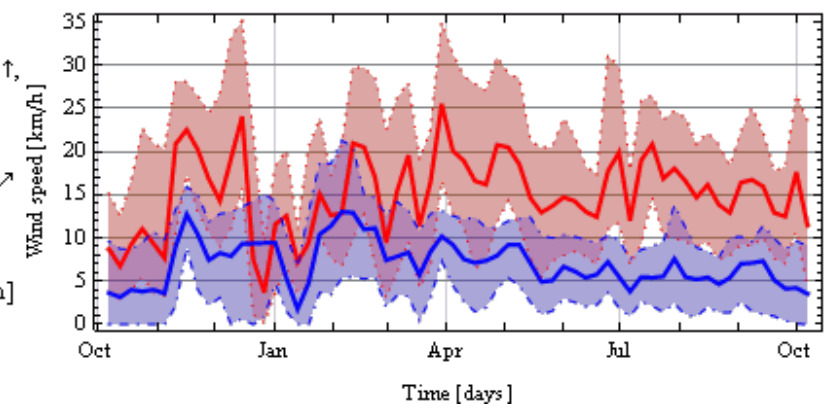

Fig. 16. Phase difference between the periodogram and spectrogram of Zaragoza airport respect the ones of Logroño airport (estimated by WINDFREDOM program). 


\section{References}

2009/28/EC of the European Parliament and of the Council of 23 April 2009 on the promotion of the use of energy from renewable sources and amending and subsequently repealing Directives 2001/77/EC and 2003/30/EC.

Akhmatov, V. \& Knudsen, H. (2002). An aggregate model of a grid-connected, large scale, offshore wind farm for power stability investigations-importance of windmill mechanical system. Electrical Power Systems 24 (2002) 709-717.

Anderson, C. L.; Cardell, J. B. (2008), Reducing the Variability of Wind Power Generation for Participation in Day Ahead Electricity Markets, Proceedings of the 41st Hawaii International Conference on System Sciences - 2008.

Antoniou, I.; Wagner, R.; Pedersen, S.M.; Paulsen, U.S.; Aagaard Madsen, H.; Jørgensen, H.E.; Thomsen, K.; Enevoldsen, P.; Thesbjerg, L., (2007), Influence of wind characteristics on turbine performance, EWEC 2007.

Apt, J. (2007) “The spectrum of power from wind turbines", Journal of Power Sources, 169, pp. 369-374

Boyle G. (2007). Renewable Electricity and the Grid. The Challenge of Variability, September 2007, Earthscan.

Burton T, Sharpe D, Jenkins N, Bossanyi E., Wind Energy Handbook. John Wiley \& Sons Ltd, England, 2001.

Cappers, P.; Goldman, C.; Kathan, D (2009), Demand response in U.S. electricity markets: Empirical evidence, Energy (article in Press).

Cidrás, J.; Feijóo, A.E.; Carrillo González, C. (2002). Synchronization of Asynchronous Wind Turbines, IEEE Trans, on Energy Conv., Vol. 17, No 4, Nov. 2002, pp 1162-1169

Constantinescu, E.M.; Zavala, V.M.; Rocklin, M; Lee, S. \& Anitescu, M (2009). Unit Commitment with Wind Power Generation: Integrating Wind Forecast Uncertainty and Stochastic Programming, Argonne National Laboratory, September 2009

Cushman-Roisin, B. (2007) Environmental Fluid Mechanics, John Wiley \& Sons, 2007.

DeCarolis, J. F.; Keith, D.W. (2005). The Costs of Wind's Variability: Is There a Threshold?, The Electricity Journal, Volume 18, Issue 1, pp. 69-77.

Dolan, D. S. L. \& Lehn, P. W. (2005), Real-Time Wind Turbine Emulator Suitable for Power Quality and Dynamic Control Studies, International Conference on Power Systems Transients (IPST'05) in Montreal, Canada on June 19-23, 2005.

Dolan, D. S. L. \& Lehn, P. W. (2006), Simulation Model of Wind Turbine 3p Torque Oscillations due to Wind Shear and Tower Shadow, IEEE Trans. Energy Conversion, Sept. 2006, Vol. 21, N. 3, pp. 717-724.

EnerNex Corporation, "Final Report - 2006 Minnesota Wind Integration Study Volume 1," Nov. 30, 2006, Available: http://www.puc.state.mn.us/docs/ windrpt_vol\%201.pdf

Feldman, S. (2009) The Wind Power Variability Myth Gets Debunked, Again, SolveClimate, Jul 17th, 2009.

Fernandez, L.M.; Saenz, J.R.; Jurado, F. (2006), Dynamic models of wind farms with fixed speed wind turbines, Renewable Energy, 31 (8), pp.1203-1230, Jul 2006. 
Frandsen, S.; Jørgensen, H.E. \& Sørensen, J.D. (2007), Relevant criteria for testing the quality of turbulence models, 2007 EWEC, Milan (IT), 7-10 May 2007. (2007) p. 128132.

Gordon-Leishman, J. (2002). Challenges in Modeling the Unsteady Aerodynamics of Wind Turbines, 21st ASME Wind Energy Symposium, Reno, NV, Jan. 14-17, 2002.

Hansen, A. D.; Iov, F.; Sørensen, P.; Cutululis, N.; Jauch, C.; Blaabjerg, F. (2007). Dynamic wind turbine models in power system simulation tool DIgSILENT, Risø National Laboratory, Roskilde, Denmark August 2007, Risø-R-1400(ed.2)(EN).

Hansen, A. D.; Jauch, C.; Sørensen, P.; Iov, F. \& Blaabjerg, F. (2003). Dynamic wind turbine models in power system simulation tool DIgSILENT, Risø National Laboratory, Roskilde, December 2003, Risø-R-1400(EN).

Heier, S. (2006), Grid Integration of Wind Energy Conversion Systems. John Wiley \& Sons, New York 2006 ( $2^{\text {nd }}$ edition).

Hirst, E. \& Hild, J. (2004), The Value of Wind Energy as a Function of Wind Capacity, The Electricity Journal, Volume 17, Issue 6, pp. 11-20, 2004.

Holttinen, H. (2008), Estimating the impacts of wind power on power systems - summary of IEA Wind collaboration, Environ. Res. Lett., 3, 2, 2008.

Holttinen, H.; Lemström, B.; Meibom, P.; Bindner, H.; Orths, A.; van Hulle, F.; Ensslin, C.; Tiedemann, A.; Hofmann, L.; Winter, W.; Tuohy, A.; O'Malley, M.; Smith, P.; Pierik, J.; Olav Tande, J.; Estanqueiro, A.; Ricardo, J.; Gomez, E.; Söder, L.; Strbac, G.; Shakoor, A.; Smith, J. C.; Parsons, B.; Milligan, M. \& Wan, Y. H. (2007). Design and Operation of Power Systems with Large Amounts of Wind Power. State-of-the-art report. VTT Technical Research Centre of Finland, 2007.

IEA (2006), IEA Wind Energy Annual Report 2006, July 2006

IEC 61400-1 (2005), Wind Turbines-Part 1: Design Requirements, Int. Std., 3rd Ed. 2005-08.

International Energy Agency, (2005). Variability Of Wind Power And Other Renewables. Management options and strategies, 2005. Available: http://www.iea.org /textbase/papers/2005/variability.pdf

Juban, J.; Fugon, L. \& Kariniotakis G. (2008) Uncertainty Estimation of Wind Power Forecasts, EWEC 2008, Brussels, Belgium.

Kazachkov, S. Stapleton, (2004), Modeling wind farms for power system stability studies, Power Technology Newsletter, Issue 95, April 2004.

Lamont, A D. (2008). Assessing the long-term system value of intermittent electric generation technologies, Energy Economics, 30 (2008), pp. 1208-1231

Mann J. (1998), Wind Field Simulation. Probabilistic Engineering Mechanics, vol. 13, nº 4, 1998, 269-282.

Martí, I.; Kariniotakis, G.; Pinson, P.; Sanchez, I.; Nielsen, T. S.; Madsen, H.; Giebel, G.; Usaola, J.; Palomares, A.M.; Brownsword, R.; Tambke, J.; Focken, U.; Lange, M.; Sideratos, G. \& Descombes, G. (2006), Evaluation of Advanced Wind Power Forecasting Models - Results of the Anemos Project, EWEC 2006, Athens. 
Martins, A; Costa, P. C. \& Carvalho A. S., (2006) Coherence And Wakes In Wind Models For Electromechanical And Power Systems Standard Simulations, European Wind Energy Conferences, EWEC 2006.

Matevosyan, J. (2006), Wind power integration in power systems with transmission bottlenecks, KTH, Stockholm, 2006.

Matos, M. A. \& Bessa, R. (2009). Operating Reserve Adequacy Evaluation using Uncertainties of Wind Power Forecast, IEEE Bucharest PowerTech Conference, June $28^{\text {th }} 2009$.

Milborrow, D. (2009), Managing Variability, A report to WWF-UK, RSPB, Greenpeace UK and Friends of the Earth EWNI, 24 June 2009.

Milligan, M. (2000) Modelling Utility-Scale Wind Power Plants. Part 2: Capacity Credit. Wind Energy, 3, pp. 167-206, 2000.

Mur-Amada, J. (2009). WINDFREDOM: WIND variability in the FREquency DOMain. Program under the GNU General Program License, available freely at http:/ / www.windygrid.org/software.

Mur-Amada, J.; Bayod-Rújula, A.A.; Ortiz, S.; Zapata, R. (2003). Power Quality Analysis of Wind Turbines. Part II - Dynamic Analysis, ICREP 2003, Vigo.

Nichita, C.; Luca, D.; Dakyo, B. \& Ceanga, E. (2002). Large Band Simulation of the Wind Speed for Real Time Wind Turbine Simulators, IEEE Transs On Energy Conversion, Vol. 17, No. 4, December 2002.

Parsons, B.; Milligan, M.; Zavadil, B.; Brooks, D.; Kirby, B.; Dragoon, K. \& Caldwell, J. (2004), Grid Impacts of Wind Power: A summary of recent studies in the United States, Wind Energy, vol. 7, Apr./Jun. 2004, pp 87-108.

Parsons, B.; Wan, Y. \& Kirby, B. (2001), Wind Farm Power Fluctuations, Ancillary Services, and System Operating Impact Analysis Activities in the United States, National Renewable Energy Laboratory, 2001

Pedersen, T. F.; Dahlberg, J.-Å.; Cuerva, A.; Mouzakis, F.; Busche, P.; Eecen P.; Sanz-Andres, A.; Franchini, S. \& Petersen, S. M. (2006), ACCUWIND -Accurate Wind Speed Measurements in Wind Energy, Risø National Laboratory, Roskilde, Denmark, July 2006.

Petru, T. \& Thiringer T. (2002), Modeling of Wind Turbines for Power System Studies, IEEE Trans. On Power Systems, Vol. 17, No. 4, Nov. 2002, pp. 1132 - 1139

Piwko, R.; Boukarikm, G.; Clark, K.; Haringa, G.; Jordan, G.; Miller, N.; Zhou, Y.; Zimberlin, J.; (2004). The Effects of Integrating Wind Power on Transmission System Planning, Reliability, and Operations. GE Power Systems Energy Consulting. Schenectady, NY. Available: http://www.nyserda.org / publications/wind_integration_report.pdf

Porter, K.; Yen-Nakafuji D. \& Morgenstern, B. (2007), A Review of the International Experience with Integrating Wind Energy Generation, The Electricity Journal, Volume 20, Issue 8, October 2007, pp. 48-59.

Pöyry PLC, Impact of intermittency. How wind intermittency could shape the electricity markets?, 01 July 2009. Available at http://www.ilexenergy.com/

Ramirez-Rosado, I. J.; Fernandez-Jimenez, L. A.; Monteiro, C; Sousa, J.; Bessa, R. (2009), Comparison of two new short-term wind-power forecasting systems, Renewable Energy, 2009 (article in Press). 
Rosas, P. (2003). Dynamic influences of wind power on the power system, Ph. D Thesis, Ørsted •DTU, March 2003, ISBN: 87-91184-16-9.

Saranyasoontorn, K.; Manuel, L. \& Veers, P. S. (2004), On estimation of coherence in inflow turbulence based on field measurements, Proceedings of the 2004 ASME Wind Energy Symposium, pp. 424-434, Reno, Nevada, January 2004.

Saranyasoontorn, K.; Manuel, L. \& Veers, P. S. (2004). A Comparison of Standard Coherence Models form Inflow Turbulence With Estimates from Field Measurements, Journal of Solar Energy Engineering, Vol. 126 (2004), Issue 4, pp. 1069-1082.

Schlez, W. \& Infield, D. (1998), Horizontal, two point coherence for separations greater than the measurement height, Boundary-Layer Meteor. 87 (1998), 459-480.

Snieckus, D. (2009). Myth of wind variability problems debunked, Recharge News, July 9 2009.

Sørensen, P.; Cutululis, N. A.; Vigueras-Rodríguez, A.; Madsen, H.; Pinson, P.; Jensen, L. E.; Hjerrild, J. and Donovan, M. (2008). Modelling of Power Fluctuations from Large Offshore Wind Farms, Wind Energy, 2008.

Sørensen, P.; Cutululis, N. A.; Vigueras-Rodríguez, A.; Madsen, H.; Pinson, P.; Jensen, L. E.; Hjerrild, J. \& Donovan, M. (2007), Modelling of Power Fluctuations from Large Offshore Wind Farms, Wind Energy, Oct 2007.

Sørensen, P; Hansen, A. D. \& Carvalho Rosas, P. A. (2002). Wind models for simulation of power fluctuations from wind farms, Journal of Wind Engineering and Industrial Aerodynamics, Vol. 90, No. 12-15, Dec. 2002, pp. 1381-1402.

Sovacool, B. K. (2009), The intermittency of wind, solar, and renewable electricity generators: Technical barrier or rhetorical excuse?, Utilities Policy, 17, (2009), 288296

Tamura, Y.; Karrem, A.; Solari, G.; Kwok, K. C. S. \& Holmes, J. D. (2003). Report from IAWE Working Group WGE-Dynamic Response. 2003.

The Guardian, 2008-07-30. Report finds US is world's top wind producer. http://www.guardian.co.uk/environment/2008/jul/30/windpower.energy.

U.S. Department of Energy (2008) 20\% Wind Energy by 2030. Increasing Wind Energy's Contribution to U.S. Electricity Supply, July 2008.

U.S. Department of Energy, (2005), Wind Energy Myths, Wind Powering America Fact Sheet Series, May 2005.

UK's National Grid, Operating the Electricity Transmission Networks in 2020. Initial Consultation. June 2009.

van Engelen, T.G. (2007). Control design based on aero-hydro-servo-elastic linear models from TURBU (ECN), EWEC 2007.

Veers PS. Three-Dimensional Wind Simulation. Sandia Report, SAND88-0152 1 UC-261, 1988.

Wan, Y; Bucaneg, D. (2002). Short-term power fluctuations of large wind power plants, Journal of Solar Energy Engineering, 124, pp. 427-431, 2002

Watson, S. (2003), Introduction to the Atmospheric Boundary Layer, CREST MSc Flexible \& Distance Learning Series. Wind Power Fundamentals. Crest, Lougborough University, 2003. 
Welfonder, E.; Neifer, R.; and Spaimer, M.; (1997), Development And Experimental Identification Of Dynamic Models For Wind Turbines, Control Eng. Practice, Vol. 5, No. 1, pp. 63-73, 1997. 


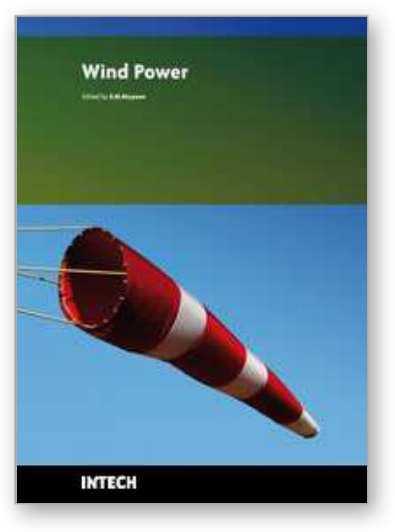

\author{
Wind Power \\ Edited by S M Muyeen
}

ISBN 978-953-7619-81-7

Hard cover, 558 pages

Publisher InTech

Published online 01, June, 2010

Published in print edition June, 2010

This book is the result of inspirations and contributions from many researchers of different fields. A wide verity of research results are merged together to make this book useful for students and researchers who will take contribution for further development of the existing technology. I hope you will enjoy the book, so that my effort to bringing it together for you will be successful. In my capacity, as the Editor of this book, I would like to thanks and appreciate the chapter authors, who ensured the quality of the material as well as submitting their best works. Most of the results presented in to the book have already been published on international journals and appreciated in many international conferences.

\title{
How to reference
}

In order to correctly reference this scholarly work, feel free to copy and paste the following:

Joaquin Mur-Amada and Angel Bayod-Rujula (2010). Variability of Wind and Wind Power, Wind Power, S M Muyeen (Ed.), ISBN: 978-953-7619-81-7, InTech, Available from: http://www.intechopen.com/books/windpower/variability-of-wind-and-wind-power

\section{INTECH}

open science | open minds

\section{InTech Europe}

University Campus STeP Ri

Slavka Krautzeka 83/A

51000 Rijeka, Croatia

Phone: +385 (51) 770447

Fax: +385 (51) 686166

www.intechopen.com

\section{InTech China}

Unit 405, Office Block, Hotel Equatorial Shanghai

No.65, Yan An Road (West), Shanghai, 200040, China

中国上海市延安西路65号上海国际贵都大饭店办公楼405单元

Phone: +86-21-62489820

Fax: $+86-21-62489821$ 
(C) 2010 The Author(s). Licensee IntechOpen. This chapter is distributed under the terms of the Creative Commons Attribution-NonCommercialShareAlike-3.0 License, which permits use, distribution and reproduction for non-commercial purposes, provided the original is properly cited and derivative works building on this content are distributed under the same license. 